\title{
The Caltech Photooxidation Flow Tube reactor: design, fluid dynamics and characterization
}

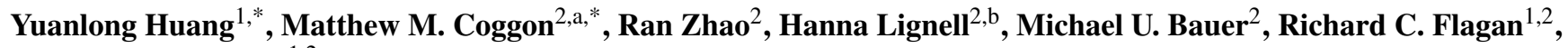 \\ and John H. Seinfeld ${ }^{1,2}$ \\ ${ }^{1}$ Department of Environmental Science and Engineering, California Institute of Technology, Pasadena, CA, USA \\ ${ }^{2}$ Division of Chemistry and Chemical Engineering, California Institute of Technology, Pasadena, CA, USA \\ ${ }^{a}$ now at: CIRES, University of Colorado, and NOAA Earth System Research Laboratory, Boulder, CO, USA \\ bnow at: South Coast Air Quality Management District, Diamond Bar, CA, USA \\ ${ }^{*}$ These authors contributed equally to this work. \\ Correspondence to: John H. Seinfeld (seinfeld@ caltech.edu)
}

Received: 29 August 2016 - Discussion started: 22 September 2016

Revised: 7 February 2017 - Accepted: 24 February 2017 - Published: 9 March 2017

\begin{abstract}
Flow tube reactors are widely employed to study gas-phase atmospheric chemistry and secondary organic aerosol (SOA) formation. The development of a new laminar-flow tube reactor, the Caltech Photooxidation Flow Tube (CPOT), intended for the study of gas-phase atmospheric chemistry and SOA formation, is reported here. The present work addresses the reactor design based on fluid dynamical characterization and the fundamental behavior of vapor molecules and particles in the reactor. The design of the inlet to the reactor, based on computational fluid dynamics (CFD) simulations, comprises a static mixer and a conical diffuser to facilitate development of a characteristic laminar flow profile. To assess the extent to which the actual performance adheres to the theoretical CFD model, residence time distribution (RTD) experiments are reported with vapor molecules $\left(\mathrm{O}_{3}\right)$ and submicrometer ammonium sulfate particles. As confirmed by the CFD prediction, the presence of a slight deviation from strictly isothermal conditions leads to secondary flows in the reactor that produce deviations from the ideal parabolic laminar flow. The characterization experiments, in conjunction with theory, provide a basis for interpretation of atmospheric chemistry and SOA studies to follow. A 1-D photochemical model within an axially dispersed plug flow reactor (AD-PFR) framework is formulated to evaluate the oxidation level in the reactor. The simulation indicates that the $\mathrm{OH}$ concentration is uniform along the reactor, and an $\mathrm{OH}$ exposure $\left(\mathrm{OH}_{\exp }\right)$ ranging from $\sim 10^{9}$ to $\sim 10^{12}$ molecules $\mathrm{cm}^{-3} \mathrm{~s}$ can be achieved from photolysis of
\end{abstract}

$\mathrm{H}_{2} \mathrm{O}_{2}$. A method to calculate $\mathrm{OH}_{\text {exp }}$ with a consideration for the axial dispersion in the present photochemical system is developed.

\section{Introduction}

Experimental evaluation of atmospheric chemistry and aerosol formation is typically carried out in laboratory reactors. Such reactors comprise both chambers and flow reactors. The flow tube reactor has emerged as a widely used platform (Bruns et al., 2015; Chen et al., 2013; Ezell et al., 2010; Kang et al., 2007, 2011; Karjalainen et al., 2016; Keller and Burtscher, 2012; Khalizov et al., 2006; Lambe et al., 2011a, b, 2012, 2015; Li et al., 2015; Ortega et al., 2013, 2016; Palm et al., 2016; Peng et al., 2015, 2016; Simonen et al., 2016; Tkacik et al., 2014).

The flow tube reactor is generally operated under steadystate conditions. An attribute of the flow tube reactor is that, by control of the inlet concentration and oxidation conditions, it is possible to simulate atmospheric oxidation under conditions equivalent to multiple days of atmospheric exposure with a reactor residence time over a range of minutes. It should be noted that the chemistry occurring in such a highly oxidizing environment may differ from that in the atmosphere and batch chamber, even though no discrepancy between the components of the secondary organic aerosol (SOA) generated in the flow tube reactor and the batch cham- 
ber has yet to be reported (Lambe et al., 2015). Moreover, under the steady-state operating conditions, it is possible to accumulate sufficient products for detailed analytical evaluation. Key factors relevant to atmospheric processes, such as gas-phase kinetics (Donahue et al., 1996; Howard, 1979; Thornton and Abbatt, 2005), nucleation rates (Mikheev et al., 2000), uptake coefficients of vapors on particles (Matthews et al., 2014) and heterogeneous reactions on particle surfaces (George et al., 2007), can be evaluated via flow tube studies.

Since the concept of potential aerosol mass (PAM) was proposed, the PAM reactor, operated as a flow tube reactor, has been widely used in laboratory and field studies of SOA formation (Chen et al., 2013; Kang et al., 2007, 2011; Keller and Burtscher, 2012; Kroll et al., 2009; Lambe et al., 2011a, 2012, 2015; Ortega et al., 2016, 2013; Palm et al., 2016; Slowik et al., 2012; Smith et al., 2009). A powerful attribute of the PAM and subsequent flow reactors is the capability to generate hydroxyl radical $(\mathrm{OH})$ levels that lead to integrated $\mathrm{OH}$ exposure ranging as high as $\sim 10^{12}$ molecules $\mathrm{cm}^{-3} \mathrm{~s}$, at which it is possible to simulate atmospheric oxidation conditions comparable to those occurring over $\sim 1$ week. Chemical kinetic modeling studies have investigated the free radical chemistry in the oxidation flow reactor (OFR) (e.g., Li et al., 2015; Peng et al., 2015, 2016).

Flow tube designs vary in dimension, detailed construction and strategy for generating the oxidizing environment. Each specific design aspect of a flow reactor can significantly affect both the fluid dynamics and the chemistry within the reactor. For example, the design of the inlet to the reactor determines the extent of initial mixing of the reactants as well as the development of concentration profiles in the reactor. The classical flow tube for gas-phase kinetic measurements employs a movable inlet in the axial position surrounded by a carrier gas to achieve the flexibility in varying reaction time (Howard, 1979). The wavelength-dependent radiation source determines the choice of oxidants that initiate free radical chemistry. In the atmosphere, the ubiquitous oxidant $\mathrm{OH}$ is generated largely by the reaction of $\mathrm{H}_{2} \mathrm{O}$ with $\mathrm{O}\left({ }^{1} \mathrm{D}\right)$, which is produced by the photolysis of $\mathrm{O}_{3}$ at wavelengths $<320 \mathrm{~nm}$. In the flow reactor, a variety of $\mathrm{OH}$ generation strategies exist. One option is to use blacklights that center around $350 \mathrm{~nm}$ to gently photolyze $\mathrm{OH}$ precursors such as $\mathrm{H}_{2} \mathrm{O}_{2}$, $\mathrm{HONO}$ and $\mathrm{CH}_{3} \mathrm{ONO}$. The material of the flow tube determines the placement of radiation sources. For example, the PAM reactor described by Kang et al. (2007) is constructed of Teflon, which is transparent to UV radiation; consequently, the UV lamps that drive the photochemistry can be positioned outside the reactor itself. By contrast, another class of flow reactors is constructed of aluminum, for which the UV lamps must be positioned inside the reactor itself (Li et al., 2015; Ezell et al., 2010). Characterization of the behavior of the flow tube reactor requires ideally a combination of flow and residence time modeling and experiment, chemical kinetic modeling and experiment, and mod- eling and experimental measurement of interactions of vapor molecules and particles with reactor walls.

We present here the development and characterization of the Caltech Photooxidation Flow Tube reactor (CPOT). The CPOT has been constructed as a complement to the Caltech $24 \mathrm{~m}^{3}$ batch chambers (Bates et al., 2014, 2016; Schilling et al., 2015; Hodas et al., 2015; Loza et al., 2013, 2014; McVay et al., 2014, 2016; Nguyen et al., 2014, 2015; Schwantes et al., 2015; Yee et al., 2013; Zhang et al., 2014; X. Zhang et al., 2015) in carrying out studies of SOA formation resulting from the oxidation of volatile organic compounds (VOCs) by oxidants $\mathrm{OH}, \mathrm{O}_{3}$ and $\mathrm{NO}_{3}$ over timescales not accessible in a batch chamber. Due to its steady-state operation, the CPOT also affords the capability to collect sufficient quantities of SOA generated in the reactor for comprehensive composition determination by offline mass spectrometry.

While the reactor itself is not unlike a number of those already developed and cited above, we endeavor here to describe in some detail the theoretical-experimental characterization of the reactor. Using computational fluid dynamics (CFD) simulations, we describe the design and characterization of the CPOT. We highlight fundamental consideration of the design of a laminar flow tube reactor, including methods of injection of gases and particles, the behavior of vapor molecules and particles in the reactor, and effects of nonisothermal conditions on the flow in the reactor. We evaluate the extent to which the fluid dynamics modeling agrees with experimental residence time distribution (RTD) measurements.

Experimental measurements of SOA formation in laboratory Teflon chambers are influenced by deposition of both particles and vapors to the chamber walls, and evaluation of the SOA yield from VOC oxidation must take careful accounting for such wall losses (e.g., Zhang et al., 2014; Nah et al., 2017, 2016). We seek to assess the extent to which both vapor and particle deposition onto the entrance region and quartz wall of the flow tube is influential in flow tube reactor studies. While experimental measurements of these processes will be presented in future studies, the transport modeling presented here provides a basis for evaluating the effect of reactor surfaces on experimental measurements of atmospheric chemistry and SOA formation.

A photochemical kinetic model is formulated to simulate $\mathrm{OH}$ production in the reactor. Typically, at steady state, the flow tube reactor gives only one data point under a specific condition. Such a model is essential in evaluating oxidation data in the reactor since the model predicts how the reactants evolve along the reactor. Generally, the ideal plug flow reactor (PFR) framework is used in the modeling of a flow tube system (Li et al., 2015; Peng et al., 2015, 2016). For a non-ideal flow reactor, the axially dispersed plug flow reactor (AD-PFR) framework couples the RTD with the chemical reaction system. The axial dispersion plays the role of backward and forward mixing of the reactants, smoothing the concentration gradients. By the comparison between AD- 
(a) System overview

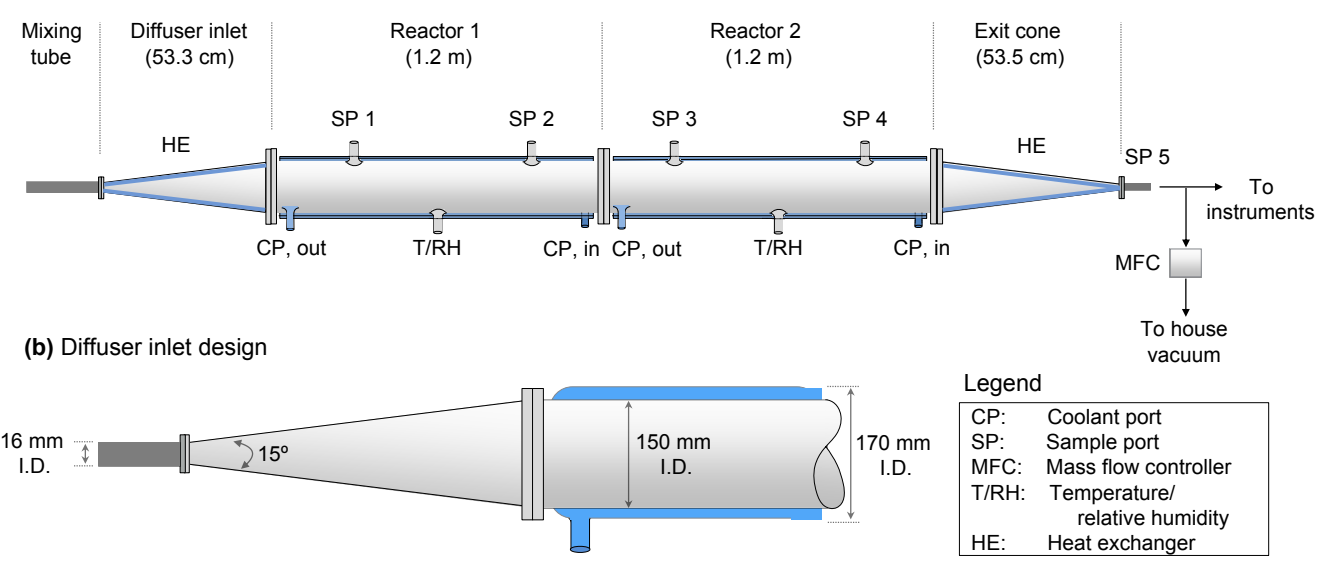

(c) Injection scheme

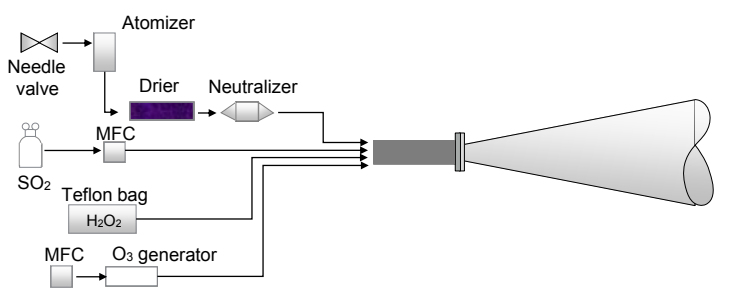

(d) UV light housing

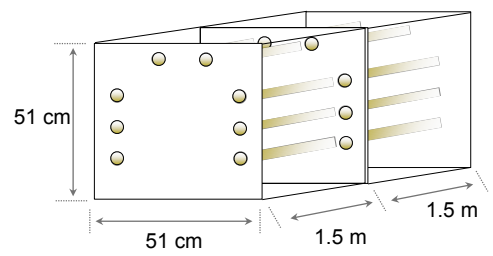

Figure 1. Overall schematic of the Caltech Photooxidation Flow Tube (CPOT). (a) The inlet design. (b) The injection scheme. (c) Schematic for the housing chamber. (d) UV lamps.

PFR and PFR models, we will show how the non-ideal flow reactor impacts the data interpretation and suggest a method for correction.

\section{Design and experimental setup}

\subsection{CPOT reactor}

The CPOT comprises three sections: the inlet section, the main reaction section and the outlet section (Fig. 1a). The inlet consists of two components - the static mixer and the conical diffuser (Fig. 1b). The static mixer is designed to thoroughly mix reactant streams, whereas the diffuser serves to expand the mixed flow to the diameter of the reaction section while maintaining an idealized laminar flow profile. The static mixer is constructed of stainless steel and consists of 12 helical elements (StaticMixCo, NY). The Pyrex glass diffuser section expands from an inner diameter of 1.6 to $15 \mathrm{~cm}$ at an angle of $15^{\circ}$. The diffuser angle was chosen based on CFD simulations in order to minimize flow separation and recirculation. Detailed design of the inlet section is discussed in Sect. 3.

The CPOT reaction section consists of two $1.2 \mathrm{~m} \times 17 \mathrm{~cm}$ ID cylindrical quartz tubes surrounded by an external water jacket ( $1 \mathrm{~cm}$ thickness) and flanged together with clamps and chemically resistant O-rings. Four ports along the reac- tor axis allow sampling of the reactor contents at different residence times. A transition cone at the end of the reactor concentrates the reactants into a common sampling line that can be split among multiple instruments; thus, samples extracted at the end of the reactor represent the so-called cupmixed average of the entire reactor cross section. This design is similar to the exit cone of the UC Irvine flow tube reactor (Ezell et al., 2010). The Pyrex glass exit cone gradually reduces the diameter of the reactor from 15 to $0.72 \mathrm{~cm}$ at an angle of $15^{\circ}$. Similar to the inlet diffuser, the exit cone is temperature controlled (Sect. 2.3).

The CPOT is designed to operate under laminar flow. The essential dimensionless group that differentiates laminar vs. turbulent flow is the Reynolds number, $\operatorname{Re}=\frac{\rho U D}{\mu}$, where $\rho$ is the fluid density, $U$ is a characteristic velocity of the fluid, $\mu$ is the fluid viscosity and $D$ is the tube diameter. For cylindrical tubes, the flow is considered laminar when $R e<2100$. Under the typical CPOT flow rate $\left(2 \mathrm{~L} \mathrm{~min}^{-1}\right)$, the Reynolds numbers at the inlet cone in the cylindrical section and at the exit cone are 150, 20 and 450, respectively, well below the transition to turbulent flow.

\subsection{Photolytic environment}

The reactor is housed within a $51 \times 51 \times 300 \mathrm{~cm}$ chamber containing 16 wall-mounted UV lamps. The arrangement of the lamps is outlined in Fig. 1d. Light intensity is adjustable 
$(0,25,50,75$ and $100 \%)$, and the UV spectrum can be set to a specific wavelength range with the installation of various T12 UV lamps, including $\mathrm{Hg}$ vapor lamps (emit narrow bands at 254 and $185 \mathrm{~nm}$ ), UVB lamps (polychromatic irradiation centered at $305 \mathrm{~nm}$ ) and UVA lamps (polychromatic irradiation centered at $350 \mathrm{~nm}$ ), based on the experimental goals.

Quantification of light fluxes for each type of lamp is the prerequisite for performing photochemical experiments. A challenge associated with quantifying photon fluxes is that the flux emitted by the lamps is not necessarily that perceived by a molecule inside the reactor. Attenuation of photon fluxes can potentially arise from (1) attenuation by the quartz wall and the water jacket surrounding the experimental sections, (2) reflection and/or refraction of light inside the chamber, and (3) absorption of light by gas-phase molecules (e.g., absorption of the $185 \mathrm{~nm}$ band by $\mathrm{O}_{2}$ molecules). To overcome this challenge, we employ a method combining direct measurements and gas-phase chemical actinometry, where the directly recorded emission spectra are adjusted to the observed photolysis rate of $\mathrm{NO}_{2}\left(j_{\mathrm{NO}_{2}}\right)$. The advantage of this method is that the actual output spectra of the lamps are used, since the quantification of fluxes is based on what the molecules perceive inside the reactor. The water coolant in the jacket surrounding the tube is transparent at the UV wavelengths of interest, with the exception that it absorbs at the $185 \mathrm{~nm}$ band emitted by the Hg vapor lamps. Although the general UV cutoff of water is at $190 \mathrm{~nm}$, we observed formation of $60 \mathrm{ppb}$ of $\mathrm{O}_{3}$ with a $2 \mathrm{~L} \mathrm{~min}^{-1}$ flow rate under the full power of the $\mathrm{Hg}$ vapor lamp. The radiation intensity at $185 \mathrm{~nm}$ that penetrates into the reaction section is calculated to be about $10^{-5}$ of that at $254 \mathrm{~nm}$. The photon fluxes in the CPOT from the three types of lamps are shown in Fig. 2 with a detailed description of the determination of photon fluxes provided in Appendix A.

\subsection{Temperature control in the reaction section}

At full photolytic intensity, the lamps generate as much as $550 \mathrm{~W}$ of heat. To maintain a constant temperature and minimize convective mixing in the tube due to temperature inhomogeneity, each of the two reaction sections is fitted with a quartz cooling jacket, in which chilled water is circulated at a rate of $13 \mathrm{~L} \mathrm{~min}^{-1}$. Coolant is introduced into the jacket near the exit cone and exits at the inlet (Fig. 1a). Under typical operation, the cooling jacket can maintain the steady-state reactor temperature at a desired value between 20 and $38^{\circ} \mathrm{C}$. Under full photolytic intensity of the UVA lamps, which produce the most heating among the three types of lamps, the temperature rise of air in the reactor is $\leq 0.3 \mathrm{~K}$ at steady state. Reactor temperature control is further addressed in Sect. 3.3.

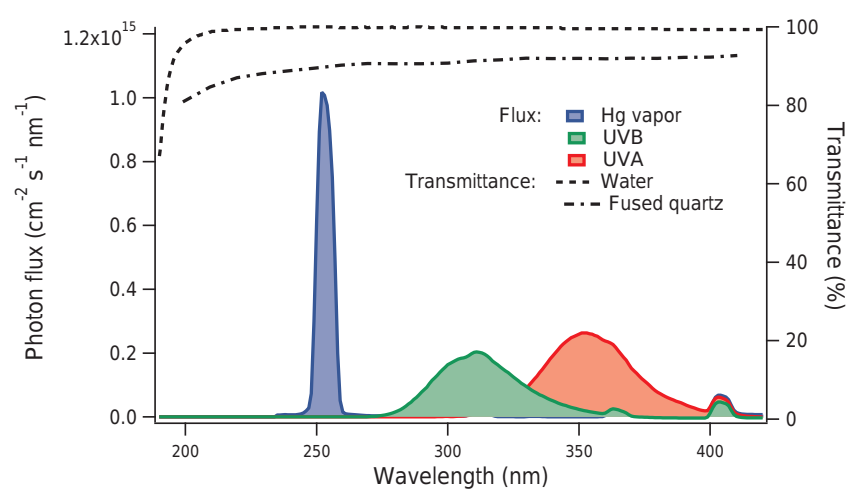

Figure 2. Photon fluxes inside the reactor, as well as the transmittance of water and fused quartz (Beder et al., 1971).

\subsection{Experimental testing}

Particles and vapor species are used to experimentally characterize the fluid dynamics inside the reactor. The injection scheme is illustrated by Fig. 1c. Polydisperse ammonium sulfate particles were generated by atomizing a $0.01 \mathrm{M}$ aqueous solution with a constant rate atomizer (Liu and Lee, 1975). The atomized particles were immediately dried by a silica gel diffusion drier. The size distribution of particles was measured by a custom-built scanning mobility particle sizer (SMPS). For the particle RTD measurement, the particle counts were monitored with a TSI 3010 condensation particle counter (CPC, Minneapolis, MN). Gas-phase RTD studies were performed under dark conditions. $\mathrm{O}_{3}$ was generated by passing purified air through an $\mathrm{O}_{3}$ generator (UVP, 97-0067-01), and the $\mathrm{O}_{3}$ mixing ratio was monitored by a $\mathrm{O}_{3}$ monitor (Horiba APOA-360). A Teledyne $\mathrm{NO}_{x}$ Analyzer (Model T200) was used to monitor $\mathrm{NO}, \mathrm{NO}_{2}$ and $\mathrm{NO}_{x}$ in the experiment of the determination of photon flux. To measure the penetration efficiency of gas-phase species, a $\mathrm{SO}_{2}$ monitor (Meloy Lab, SA285E) was used to detect $\mathrm{SO}_{2}$ and a chemical ionization mass spectrometry (CIMS, Crounse et al., 2006; St. Clair et al., 2010) was employed to detect $\mathrm{H}_{2} \mathrm{O}_{2}$.

\subsection{CFD simulations}

CFD simulations were performed using COMSOL Multiphysics 5.0 software (Stockholm, Sweden, http://www. comsol.com) to assist the design and characterization of the reactor. COMSOL uses a finite element method and has a number of built-in modules that can be utilized to simulate a specific experimental condition. Recently, several research groups have employed COMSOL in atmospheric and aerosol chemistry studies (Grayson et al., 2015; Sellier et al., 2015; Y. Zhang et al., 2015). Here, the model geometry replicates that of the actual design; thus, the simulations include a static mixer, diffuser inlet, reaction section and exit cone with exact dimensions (Fig. 3a). 
(a) COMSOL geometry

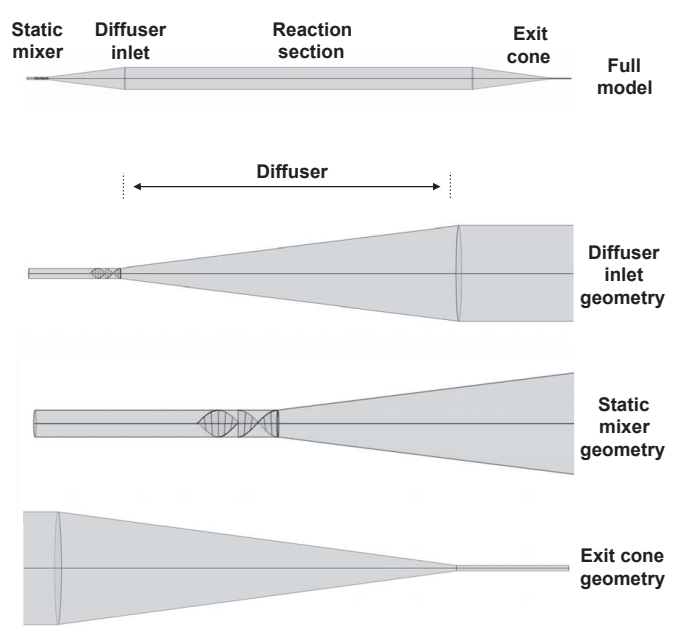

(b) Inlet meshing

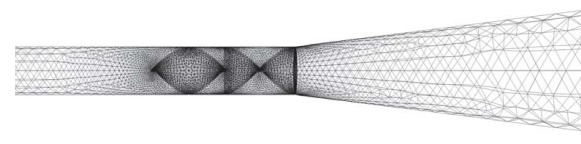

(c) Non-isothermal surface temperature

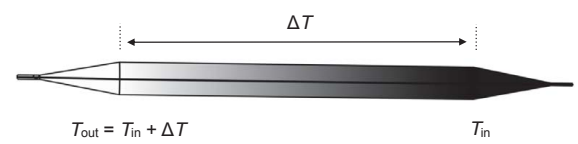

Figure 3. (a) Overview of the geometry used to simulate flow and species transport within the CPOT. (b) Inlet meshing for static mixer. (c) Schematic illustration of the temperature gradient used in non-isothermal simulations.

At the design stage, the performance of the inlet section was simulated numerically using CFD models (Sect. 2.5). The actual static mixer containing 12 mixing elements was simulated by a two-element mixer using the COMSOL builtin static mixer model. Flow profiles calculated using the two-element static mixer model were found to be identical to those using static mixers with four or more elements. Since static mixers yield asymmetric flow patterns, the model was solved in a 3-D geometry. The entire 3-D model was discretized with a fine mesh composed of approximately $1.25 \times 10^{6}$ tetrahedral elements (Fig. 3b). The average element quality, which is a reflection of cell distortion (a value of 1 reflects a perfect element shape), was 0.77 with a minimum of 0.12. A finer mesh within the domain of the static mixer was applied to capture flow dynamics near the entrance to the diffuser cone (Fig. 3b). Model sensitivity to meshing was tested using a finer mesh density, and results were found to be identical. An impermeable and no-slip boundary condition was applied to all surfaces. The flow at the entrance into the static mixer was set to be $2 \mathrm{~L} \mathrm{~min}^{-1}$, and the outlet pressure was assumed to be atmospheric. Simulations were conducted until a steady state was achieved, and the errors converged to $<10^{-6}$.

Navier-Stokes equations were solved using the COMSOL laminar flow package in the CFD module assuming compressible, isothermal flow. The isothermal assumption will be relaxed subsequently. To evaluate the effect of reactor temperature gradients, the COMSOL laminar flow package was coupled to the convective and diffusive heat transfer interface. To visualize fluid flow through the reactor, transient simulations were performed using the COMSOL dilute species transport package. This model, when coupled to the Navier-Stokes equations, enables one to track convec- tion and diffusion of a tracer species, as described in Sect. 4. After first generating the steady-state laminar flow profile, a $30 \mathrm{~s}$ rectangular pulse of a $0.1 \mathrm{~mol} \mathrm{~m}^{-3}$ tracer was introduced numerically into the reactor at the entrance to the static mixer to generate the RTD. No wall uptake of gases or particles was assumed in this computation. Molecular or Brownian diffusivity can be varied over several orders of magnitude to represent that of vapor molecules and particles. The simulation was run for $80 \mathrm{~min}$ with data output every $15 \mathrm{~s}$ (consistent with the data acquisition of the instruments, e.g., $\mathrm{O}_{3}$ monitor and CPC). Simulations were performed for a variety of different inlet geometries, flow rates and reactor temperature gradients. These simulations served to evaluate the design against alternative configurations and also demonstrate the sensitivity of fluid field to various flow conditions.

\subsection{Photochemical model}

While the CFD simulation serves as a comprehensive method to understand the fluid dynamics, it is not efficient to solve a complex chemical kinetic system within this framework. A simplified 1-D axial-dispersion photochemical model based on the RTD measurement is built here to evaluate the oxidation level. The mechanism presented here is that in the absence of $\mathrm{NO}_{x}$. The oxidation of $100 \mathrm{ppb} \mathrm{SO}_{2}$ by the $\mathrm{OH}$ radical is studied. $\mathrm{H}_{2} \mathrm{O}_{2}$ at $1 \mathrm{ppm}$ serves as the $\mathrm{OH}$ precursor. The three types of UV lamps are considered, sequentially, to investigate the effect of the radiation source on $\mathrm{OH}$ exposure. Each simulation is carried out at a relative humidity $(\mathrm{RH})$ of $5 \%$ and $T=295 \mathrm{~K}$ (corresponding to $\left[\mathrm{H}_{2} \mathrm{O}\right]=1500 \mathrm{ppm}$ ). The case in the absence of $\mathrm{H}_{2} \mathrm{O}_{2}$ input is also simulated to check the background $\mathrm{OH}$ level. Reactions of the full mechanisms and the rate coefficients including photolysis rate un- 
der different lamps that are necessary for the chemical kinetic modeling are listed in Appendix B.

The AD-PFR model setup is used in the present study and described in Appendix C. The Danckwerts boundary condition is employed to ensure the flux continuity at both the inlet and outlet (Davis and Davis, 2003). This model system is solved in MATLAB (R2015b) by a boundary value problem solver bvp 4c. The PFR model is run simultaneously as a comparison. No wall interaction and new particle formation are considered in the models. The result will be discussed in Sect. 6.

\section{Design of the flow tube reactor}

Essential elements of the design of a flow tube reactor are (1) the manner by which reactants are introduced into the reactor; (2) the nature of the flow inside the reactor; (3) the type and location of the radiation source relative to the reactor itself; and (4) the management of heat generation due to the radiation source. The first two correspond to the inlet section design, while the latter two address the problem of possible non-isothermal conditions in the reaction section.

\subsection{Injection method}

A number of possible arrangements exist to introduce material into a flow tube reactor (Fig. 4). The nature of the injection manifold has the potential to profoundly affect the flow profile in the subsequent reaction section. In the case of a laminar flow reactor, it is desirable to minimize such "end effects" in order to establish parabolic flow quickly within the reaction section; otherwise, phenomena such as jetting and recirculation have the potential to impact flow patterns throughout the entire reactor. Figure 4a depicts the simplest injection method, by which vapor and particles are introduced into the reaction section through a short injection tube. While a benefit of this design is its simplicity, with this mode of injection, it is challenging to distribute reactant mixtures evenly across the reactor cross section. We tested this inlet method on a cylindrical Pyrex glass tube and visualized the flow pattern by the injection of smoke (Fig. 4a). With flow controlled by a vacuum line attached to the exit section, the gas-particle mixture is pulled into the reaction tube at a rate that is dictated by mass conservation. Smoke visualization studies illustrate that the mixture concentrates in a plug at the center of the reactor. This "fire hose" effect arises from the enhanced velocity at the exit of the injection tube $\left(U_{\text {avg, injection }}\right)$. Such flow behavior is typical for that occurring with a sudden expansion (Bird et al., 2007).

Some flow tube designs address inlet issues using flow management devices, e.g., a spoked-hub/showerhead disk inlet (Bonn et al., 2002; Ezell et al., 2010) that distributes the reactants evenly about the reactor cross section and provides sufficient mixing (Fig. 4b). Even when reactants are intro- duced gently into the tube, an axial distance is still required for the flow to develop to the characteristic parabolic laminar flow profile. This entrance length, $L_{\text {entr }}$, is estimated to be $0.035 \mathrm{DRe}$ (Bird et al., 2007). The inlet section should be designed with a sufficient entrance length $L_{\text {entr }}$ to ensure the development of the laminar profile prior to the reaction section.

In the CPOT, reactants are injected via a conical diffuser (Fig. 4c), which has the advantage of gradually decreasing the velocity, thereby assisting with the formation of the laminar parabolic profile. The employment of a diffuser cone essentially replaces $L_{\text {entr }}$, and a parabolic profile is fully developed when the reactants reach the reaction section.

In addition to the flow field inside the reactor introduced by the inlet design, the transmission of different reactants (i.e., gas-phase species and particles) in the inlet system should also be considered (Karjalainen et al., 2016; Ortega et al., 2013, 2016; Palm et al., 2016; Simonen et al., 2016; Tkacik et al., 2014). Generally, a larger surface area means more interaction between the reactants and the walls, especially for "sticky" molecules. The effect of static mixer on the transmission of gas-phase species will be investigated in Sect. 5.1.

\subsection{Angle of the diffuser}

A key consideration in designing a diffuser is avoiding flow separation that occurs when streamlines detach from the diffuser wall. Separation may be characterized by two flow patterns: stall and jetting flow. In stall, an asymmetrical flow pattern develops due to an adverse pressure gradient. Fluid is accelerated along one wall of the diffuser and recirculates slowly back along the other wall to the point of streamline detachment (Tavoularis, 2005). As demonstrated in Fig. 4a, jetting flow is characterized by a symmetric flow pattern where the fluid is accelerated at the center of the diffuser and recirculates slowly along the walls. Recirculation introduces non-ideality since it accelerates gases and particles down the reactor, thereby affecting the RTD and leading to uncertain reaction times.

Diffusers are routinely applied in larger systems such as wind tunnels and turbines; therefore, most literature on diffuser design focuses on flow patterns at high $\operatorname{Re}(\operatorname{Re}>5000$, e.g., Mehta and Bradshaw, 1979; Seltsam, 1995; Tavoularis, 2005; Prakash et al., 2014). As a rule of thumb for high $R e$ systems, flow separation can be suppressed when the diffuser half-angle is $\leq 5^{\circ}$; however, smaller angles are needed when the area ratio between the diffuser inlet and reactor section is much greater than 5 (Mehta and Bradshaw, 1979). We are unaware of studies that report diffuser performance at modest $\operatorname{Re}(<500)$. Fried and Idel'chik (1989) recommend that diffusers be designed with an angle of divergence $<7^{\circ}$ to avoid flow separation; alternatively, White (2008) recommends an angle $<15^{\circ}$. Sparrow et al. (2009) modeled the flow of fluid 
(a) Straight tube inlet

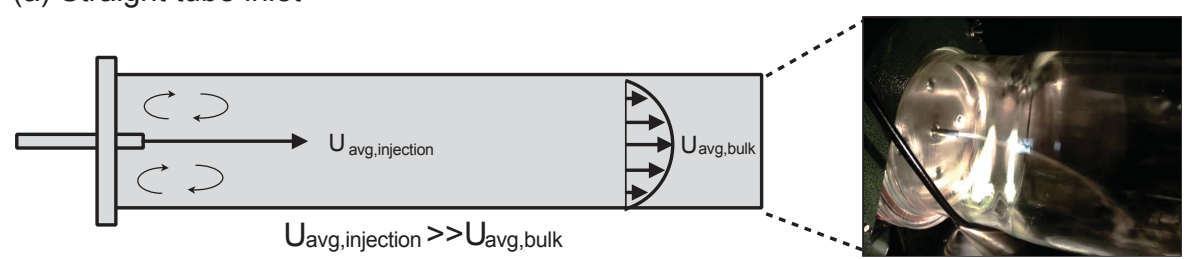

(b) Showerhead inlet

"Fire hose" effect

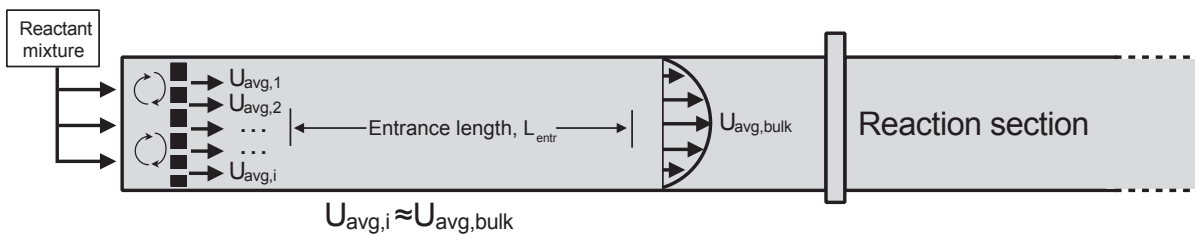

(c) Diffuser inlet

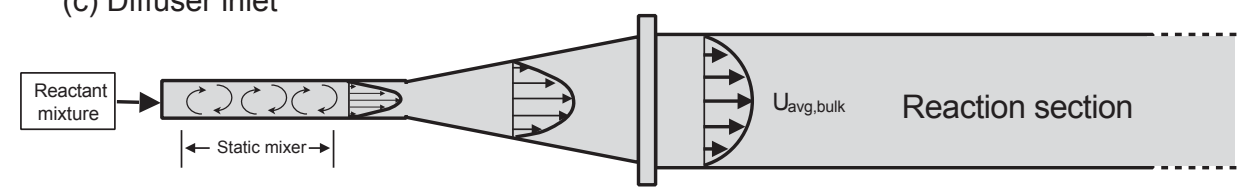

Figure 4. Inlet designs exemplified by (a) straight tube injection, (b) showerhead injection and (c) diffuser injection. $U_{\text {avg,injection }}, U_{\text {avg,bulk }}$ and $U_{\mathrm{avg}, \mathrm{i}}$ values denote the average velocities at the inlet, in the bulk reaction section and at the exit of a showerhead hole, respectively. Panel (a) also illustrates the "fire hose" effect, as demonstrated by the visualization of smoke in a Pyrex glass tube.

through diffuser cones at various $R e$. For further discussion about flow separation within diffusers, see Tavoularis (2005).

Under a typical working flow rate $\left(2 \mathrm{~L} \mathrm{~min}^{-1}\right)$, the value of $R e$ at the entrance of the conical diffuser is $\sim 200$. Figure 5 shows simulated flow profiles for a range of diffuser angles. The red traces represent streamlines, whereas the blue surface illustrates points where flow recirculation occurs, that is, where the axial velocity $<0 \mathrm{~cm} \mathrm{~s}^{-1}$. Collectively, these traces provide a visualization of the recirculation zone. We present flow profiles in the presence and absence of a static mixer since swirling flow has been shown to improve diffuser performance for systems with appreciable separation (McDonald et al., 1971).

As the diffuser angle increases, separation becomes more appreciable, and the recirculation zone penetrates farther into the reaction section $(\Delta z>0)$. At the most extreme angle we considered $\left(\theta=37^{\circ}\right)$, the simulation predicts that the first $46 \mathrm{~cm}$ of the reaction section is impacted by recirculation. For reference, the extreme of a sudden expansion $\left(\theta=90^{\circ}\right)$ exhibits recirculation that penetrates nearly halfway through the reactor $(\Delta z=110 \mathrm{~cm})$. For flow tube systems operated at similar $R e$ as here, if a parabolic flow profile is desired, it is recommended that one utilizes a diffuser with $\theta<20^{\circ}$ in order to minimize laminar flow disturbance within the reaction section.

The presence of a static mixer tends to quell separation at moderate diffuser angles. The recirculation zone appears

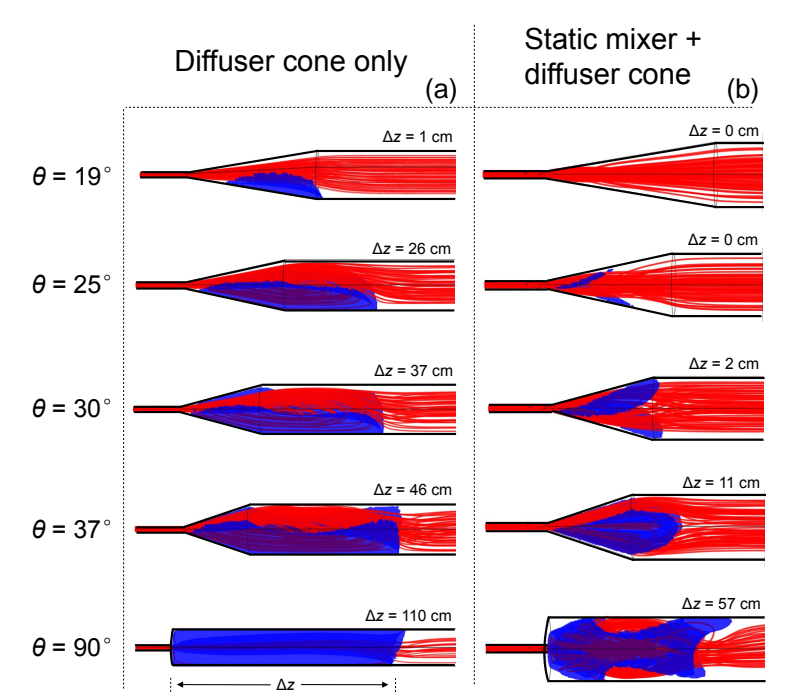

Figure 5. COMSOL simulation results for a suite of diffuser angles assuming isothermal conditions. Images in the left column are from simulations conducted in the absence of a static mixer. Images in the right column are from simulations employing a two-element static mixer upstream of the diffuser cone. The red traces are streamlines demonstrating the flow pattern of fluid introduced upstream of the static mixer. The blue surfaces illustrate regions where the axial velocity $<0 \mathrm{~m} \mathrm{~s}^{-1}$. Together, these traces illustrate the recirculation zone. $\Delta z$ is the length that the recirculation zone penetrates into the reaction section. All simulations were performed for a volumetric reactor flow of $2 \mathrm{~L} \mathrm{~min}^{-1}$. 
(a)

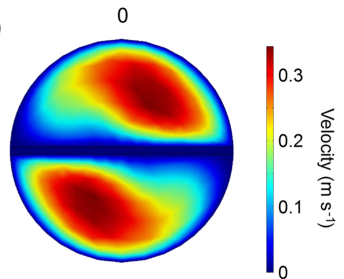

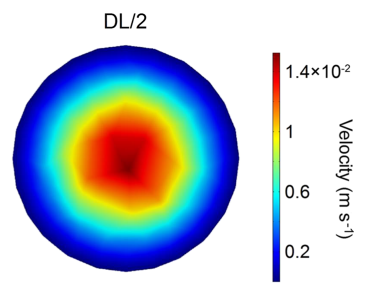

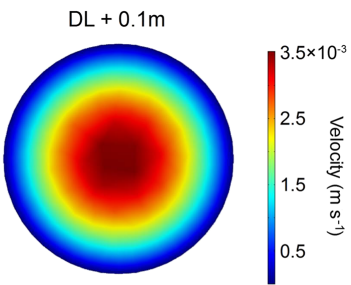

(b)

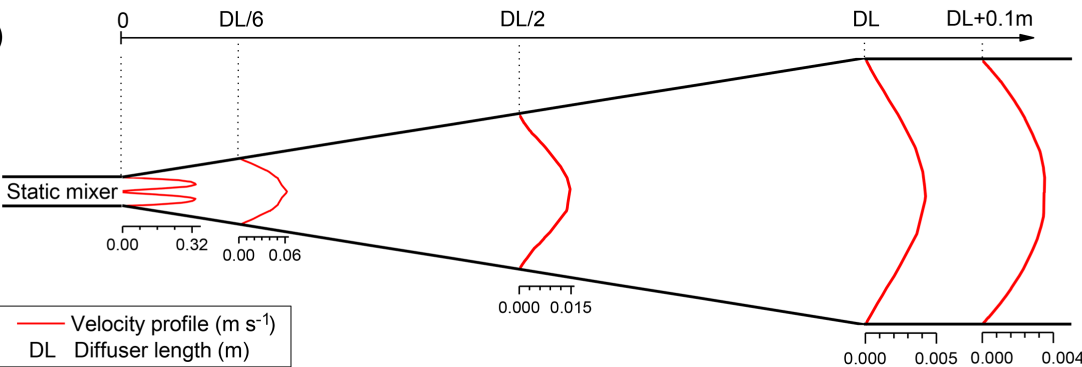

(c)

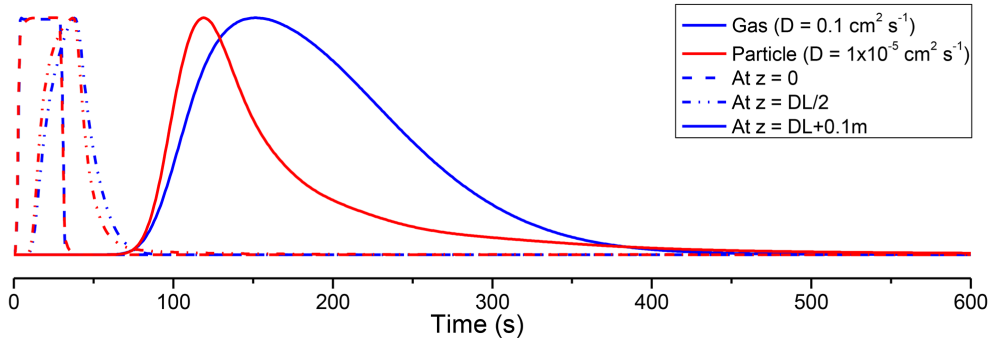

Figure 6. COMSOL simulated velocity field at the reactor inlet under isothermal conditions. Simulations were performed for the actual CPOT design: a $15^{\circ}$ diffuser cone coupled to a static mixer. The velocity magnitude at various axial positions is shown in panel (a), and 1-D axial velocity profiles within the "inlet-affected" region are shown in panel (b). The velocity magnitude in panel (b) is presented on the axis below each velocity profile. Note that DL indicates diffuser length $(53.3 \mathrm{~cm})$. Panel $(\mathbf{c})$ shows the normalized residence time of vapor molecules and monodisperse particles at various axial positions. A $30 \mathrm{~s}$ square wave pulse is used as the input.

to propagate into the reaction section only at diffuser angles $>30^{\circ}$; however, the extent of this recirculation is substantially reduced compared to simulations in the absence of a static mixer. Furthermore, the recirculation zone is predicted to be symmetric; fluid from the static mixer is directed radially towards the walls of the diffuser and recirculates back towards the center. In contrast, the recirculation zone in diffusers without static mixers is predicted to be asymmetric (Fig. 5), with flow recirculating at one wall of the diffuser. With flow introduced via a sudden expansion, the presence of a static mixer does little to minimize recirculation. The improvement in diffuser performance with swirling flow at the inlet is consistent with observations at high $R e$ (McDonald et al., 1971), suggesting that the addition of a static mixer may help to mitigate moderate separation in systems employing wide-angled diffusers.

Figure 6 further illustrates the CFD-modeled velocity profiles for the actual CPOT design, with a $15^{\circ}$ diffuser cone coupled to a static mixer, in the region of the reactor extending from the inlet cone to the first $10 \mathrm{~cm}$ of the reaction section. We refer to this section of the reactor as the "inlet- affected" region, since axial positions farther downstream exhibit fully developed laminar profiles. Figure 6a visualizes the entire velocity field along select cross sections within the inlet-affected region, whereas Fig. $6 \mathrm{~b}$ presents $1-\mathrm{D}$ velocity profiles at various axial positions. Note that Fig. 6a presents the velocity magnitude, whereas Fig. $6 \mathrm{~b}$ illustrates the axial velocity component (i.e., flow in the $z$ direction) to facilitate identification of regions impacted by flow recirculation. In general, the simulation predicts the absence of recirculation within the reactor under isothermal conditions. As demonstrated by Fig. 6b, the simulated axial velocity profile immediately downstream of the static mixer exhibits two jets with a maximum axial velocity of $31 \mathrm{~cm} \mathrm{~s}^{-1}$. The jets quickly dissipate as the flow develops through the diffuser cone. At the exit of the diffuser cone, the flow is nearly parabolic and the maximum velocity slows to $0.5 \mathrm{~cm} \mathrm{~s}^{-1}$. Within $10 \mathrm{~cm}$ of the diffuser exit, the flow becomes parabolic with a maximum centerline velocity of $0.4 \mathrm{~cm} \mathrm{~s}^{-1}$. We also simulated the fluid field under higher flow rates (e.g., 4 and $6 \mathrm{~L} \mathrm{~min}^{-1}$ ) and found no separation of flow within the diffuser. These results demonstrate that the CPOT inlet is within the design limits 
for a diffuser with non-separated flows and that the presence of a static mixer has little effect on the parabolic profile in an isothermal reaction section. However, the presence of the static mixer does have an impact on the residence time of the reactants. Figure $6 \mathrm{c}$ shows the corresponding residence time at the three positions for both vapor molecules and monodisperse particles, both of which are a $30 \mathrm{~s}$ square wave input. Section 4.3 addresses RTD.

\subsection{Non-isothermal effect}

Precise control of temperature is crucial to maintaining as well-characterized a laminar flow as possible in the reaction section (Khalizov et al., 2006; Jonsson et al., 2008). In one class of flow tube design, the radiation source is positioned within the flow tube reactor itself, and the reactor walls are constructed of a UV blocking material. In that design, the effect of the internal heat source on the flow must be taken into account. In the present design, with the reaction tube suspended at the center of the chamber and the lights positioned on the outside of the tube, an exterior water jacket provides a heat transfer medium, while allowing penetration of UV radiation to the reactor. If water recirculation in the jacket is sufficiently rapid, axial temperature gradients in the cooling jacket can be minimized. Any jacket temperature maintained appreciably below or above that in the reactor itself will lead to temperature gradients that may induce secondary flows in the reactor.

Although the CPOT is equipped with a temperature control system (Sect. 2.3), maintaining a target temperature under UV irradiation is challenging. The measured rise in coolant temperature at steady state under full irradiation conditions is $\leq 0.2 \mathrm{~K}$. Given the absence of heat sources within the reactor itself, the increase in coolant temperature is a result of the absorption of heat generated by the exterior UV lamps. Temperature gradients along the reactor wall have the potential to induce recirculation from changes in density. The establishment of radial temperature gradients near the wall induces recirculation cells as density variations force the flow to stratify.

The dimensionless group that characterizes the effect of free convection on flow is the Richardson number, which relates the strength of buoyancy forces to that of convective forces. The Richardson number (Holman, 2010), Ri, can be expressed as the ratio of the Grashof number, $G r$, to the square of the Reynolds number, $R e$ :

$R i=\frac{G r}{R e^{2}}=\frac{g \beta D^{3} \Delta T / v^{2}}{\left(\rho U_{\mathrm{avg}} D / \mu\right)^{2}} \sim \frac{g D}{T U_{\mathrm{avg}}^{2}} \Delta T$,

where $g$ is the gravitational acceleration, $\beta$ is the thermal expansion coefficient of air (1/T for ideal gases), $U_{\text {avg }}$ is the average fluid velocity, $v$ is the kinematic viscosity of air $(\mu / \rho)$ and $\Delta T$ is a characteristic temperature difference between the tube wall and centerline. When $R i<0.1$, convective forces dominate, and effects of buoyancy on the flow are small. When $R i>10$, buoyancy forces may lead to flow bifurcation and recirculation. Under typical CPOT operating conditions, a radial temperature gradient between the fluid and wall of $\sim 0.007 \mathrm{~K}$ is required to maintain $R i<10$. Because this is a very small temperature difference, modest inequalities in temperature are anticipated to affect flow patterns within the reactor.

To investigate the effect of wall temperature differences on flow within the reaction section, we performed COMSOL simulations, assuming a non-isothermal reactor wall. The COMSOL laminar flow package was coupled to the convective and diffusive heat transfer interface. Since water is assumed to flow uniformly through the annular water jacket cross section from the exit to the entrance, we apply an axial temperature gradient to the simulation. A schematic illustration of the simulation setup is shown in Fig. 3c. At the exit of the reaction section, the temperature of the reactor wall is set to that of water entering the cooling jacket $\left(T_{\text {in }}\right)$. At the entrance to the reaction section, we assume that the wall temperature is that of the water exiting the cooling jacket $\left(T_{\text {out }}=T_{\text {in }}+\Delta T\right)$. The wall temperature is assumed to change linearly between the entrance and exit. The diffuser cone is prescribed at a constant temperature equivalent to the cooling jacket temperature $T_{\text {out }}$, whereas the exit cone is prescribed a constant temperature of $T_{\mathrm{in}}$. In the following discussion, we focus on results with $T_{\text {in }}=23{ }^{\circ} \mathrm{C}$, which is the typical room temperature in the Caltech laboratory. Note that this model setup is a simplified case, since in actual experiments the entrance and exit cones should be kept at the same temperature (i.e., $T_{\text {in }}$ ); this will introduce temperature discontinuity between the entrance cone and the reaction tube. Nonetheless, this idealized model provides insight into the temperature-difference-induced flow perturbation within the flow tube reactor.

Figure 7 demonstrates the simulated effect of an axial temperature gradient $(\Delta T)$ on flow profiles within the reactor. Figure 7a illustrates $2-\mathrm{D}$ velocity profiles at various axial positions and a blue isosurface where the axial velocity $<0 \mathrm{~cm} \mathrm{~s}^{-1}$. Figure $7 \mathrm{~b}$ illustrates $1-\mathrm{D}$ velocity profiles at the midpoint of the reactor. As the temperature gradient within the reactor increases, the velocity profiles skew due to the buoyancy of the warm air. This bifurcation induces recirculation and is predicted to affect the entire reactor region. For a temperature gradient of $0.2 \mathrm{~K}$ (equivalent to that actually measured), the recirculation zone exhibits a maximum velocity of $-0.15 \mathrm{~cm} \mathrm{~s}^{-1}$.

The simulations demonstrate the sensitivity of the velocity profile in the reactor to small temperature gradients within the reaction section. Such disturbances will manifest in shorter, broader residence times due to induced recirculating flow. As demonstrated in Fig. 7, a critical temperature difference exists at which recirculation becomes important. At a volumetric flow of $2 \mathrm{~L} \mathrm{~min}^{-1}$, this critical temperature difference between the exit and the entrance is estimated to be $\sim 0.08 \mathrm{~K}$. The $R i$ number criterion indicates that higher 

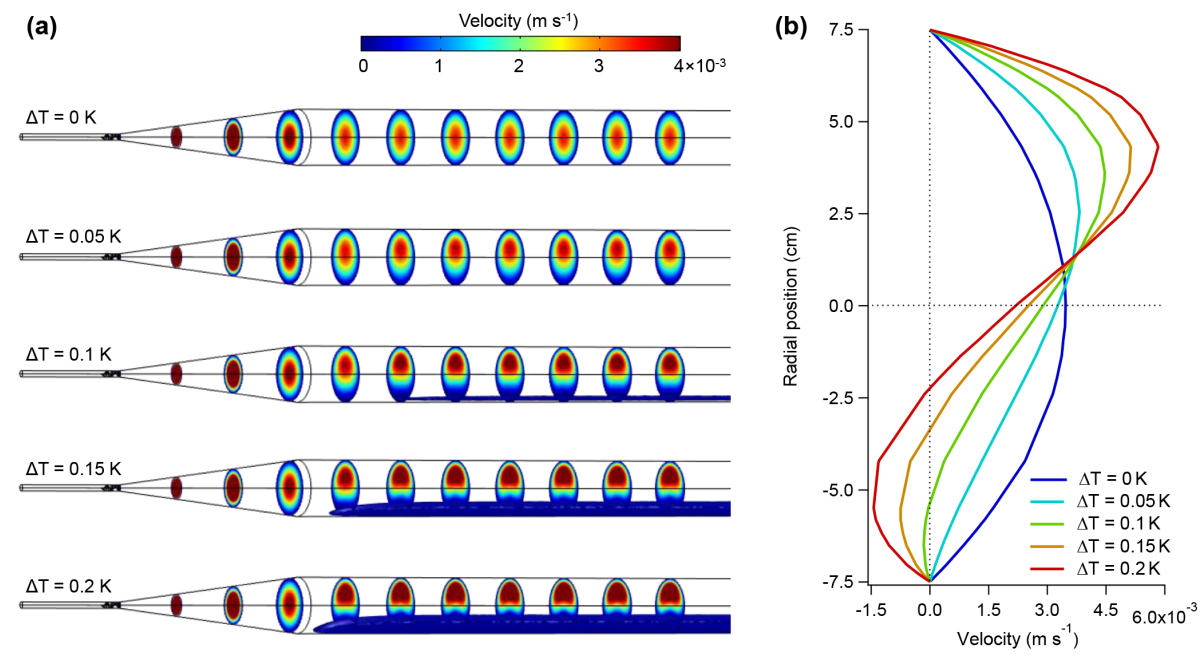

Figure 7. COMSOL simulated flow profiles as a function of reactor wall temperature gradient $\Delta T$. (a) Three-dimensional simulation results demonstrating cross-sectional velocity profiles and consequential recirculation zones (blue isosurface). (b) One-dimensional velocity profiles at axial position $z=150 \mathrm{~cm}$.

flow rates reduce the reactor sensitivity to temperature gradients. We find the critical temperature differences at 4 and $6 \mathrm{~L} \mathrm{~min}^{-1}$ are 0.18 and $0.3 \mathrm{~K}$, respectively. Even at higher flow rates, relatively small temperature gradients along the walls of the reactor can have potential consequences on reactor flow patterns.

\section{Behavior of gaseous and particulate species in a laminar flow tube reactor}

\subsection{Fluid field in the reaction section}

At the typical operating flow rate $\left(2 \mathrm{~L} \mathrm{~min}^{-1}\right)$, flow within the reaction section is laminar $(R e \cong 20)$, under which the axial fluid velocity is given by the parabolic distribution:

$v_{z}(r)=U_{\max }\left[1-\left(\frac{r}{R}\right)^{2}\right]$,

where $U_{\max }$ is the centerline velocity, $r$ is the radial coordinate in the tube and $R$ is the tube radius. The residence time of fluid elements in laminar flow differs along streamlines, for which the average residence time of fluid elements is precisely calculated. Due to the sensitivity to small temperature difference, as noted above, the actual velocity profile in the reactor under non-isothermal condition will not adhere to an ideal parabolic distribution.

\subsection{Penetration efficiency $(\eta)$}

The penetration efficiency $\eta$ is defined as the fraction of material entering the reactor that leaves in the absence of chemical reaction. If no removal occurs during flow through the reactor, then $\eta=1$. Diffusional loss in a laminar cylindrical tube is addressed in Appendix D. The mass conservation
Eqs. (D2) to (D5) can be solved either numerically or analytically (Davis, 2008) to determine the penetration efficiency $\eta$, given a first-order loss rate to the wall, $k_{\mathrm{w} i}$. For the case of complete removal of species $i$ at the wall, in which $k_{\mathrm{w}} \rightarrow \infty$, corresponding to the boundary condition $c_{i}=0$ at the wall, the analytical solution for $\eta$ is (Fuchs, 1964)

$$
\begin{aligned}
\eta= & 0.8191 \exp (-3.657 \xi)+0.0975 \exp (-22.3 \xi) \\
& +0.0325 \exp (-57 \xi)+\ldots,
\end{aligned}
$$

where $\xi$ is the dimensionless length $\left(\frac{\pi \mathcal{D} L_{\text {cyld }}}{O}\right), \mathcal{D}$ is the diffusivity of the species, $L_{\text {cyld }}$ is the length of the cylindrical tube and $Q$ is the volumetric flow rate. For small $\xi$, i.e., $<0.02$, an alternative equation is available (Gormley and Kennedy, 1948):

$\eta=1-2.56 \xi^{\frac{2}{3}}+1.2 \xi+0.177 \xi^{\frac{4}{3}}$.

The penetration efficiency for particles is size dependent, i.e., $\eta\left(D_{\mathrm{p}}\right)$. We will address the RTD of particles in Sect. 4.3.2 and Appendix F.

\subsection{Residence time distribution}

In a laminar flow field, idealized non-diffusing vapor or nondiffusing and non-settling particles, introduced as a pulse at the entrance of the tube, will first emerge as a pulse at the residence time of the centerline, followed by a decaying curve as the material on the slower streamlines reaches the exit. Under actual conditions, vapor molecules undergo molecular diffusion in both the radial and axial directions, and particles are subject to Brownian diffusion and gravitational settling. 


\subsubsection{Vapor molecule RTD}

Vapor molecules in laminar flow in a tube undergo molecular diffusion in both the radial and axial directions. With molecular diffusion coefficient $\mathcal{D}_{i}$, the characteristic diffusion time in the radial direction is $\tau_{\mathrm{c}, \mathcal{D}_{i}}=\frac{R^{2}}{\mathcal{D}_{i}}$. To assess the importance of radial diffusion as a mechanism for smearing vapor molecules across the tube cross section during convection down the tube, one can compare the characteristic timescale for radial diffusion with the characteristic residence time in the cylindrical tube, $\tau_{\mathrm{c} \text {,cyld }}=\frac{L_{\mathrm{cyld}}}{U_{\text {avg }}}$. If $\tau_{\mathrm{c}, \mathcal{D}_{i}} \ll \tau_{\mathrm{c} \text {,cyld }}$, for example, the vapor molecules will diffuse more or less uniformly across the tube radius in the time it takes for the fluid to flow to the tube exit. Likewise, if $\tau_{\mathrm{c}, \mathcal{D}_{i}} \gg \tau_{\mathrm{c}, \text { cyld }}$, each vapor molecule will effectively remain on the streamline upon which it entered. Vapor molecules also diffuse in the axial direction; this process is represented by the axial diffusion term, $\mathcal{D}_{i} \frac{\partial^{2} c_{i}}{\partial z^{2}}$, on the right-hand side of Eq. (D1). As noted earlier, for flow velocities of the magnitude of those here, the effect of this axial diffusion is negligible when compared with axial convection. However, an apparent axial diffusion can arise from the interaction of radial molecular diffusion and the laminar flow, a process known as Taylor dispersion (Taylor, 1953; Bird et al., 2007). Under the criterion, $\tau_{\mathrm{c} \text {, cyld }} \gg \frac{\tau_{\mathrm{c}, \mathcal{D}_{i}}}{3.83^{2}}$, the concentration becomes approximately uniform over the cross section of the tube. Appendix E presents a discussion of the application of Taylordispersion-based RTDs with respect to different initial conditions.

In the PAM reactor (Lambe et al., 2011a), the Taylor dispersion criteria do not strictly meet the working conditions; however, the two flow regime fitting results suggest that two types of flow may exist in the reactor: a direct flow with minor dispersion and a secondary recirculation flow with significant dispersion. Under the current flow rate of $2 \mathrm{~L} \mathrm{~min}^{-1}$ and characteristic vapor molecular diffusivity $\sim 1 \times 10^{-5} \mathrm{~m}^{2} \mathrm{~s}^{-1}$, $\tau_{\mathrm{c} \text {, cyld }}=1290 \mathrm{~s} \gg \frac{\tau_{\mathrm{c}, \mathcal{D}_{i}}}{3.83^{2}}=50 \mathrm{~s}$; therefore, the Taylor dispersion approximation for the gas-molecule RTD applies, and Taylor dispersion can be expected to be important. Note that the presence of the static mixer and conical diffuser in the inlet section alters the input distribution of vapor molecules and particles at the entrance of the reaction section (Fig. 6c) from an idealized uniform initial condition, and Eq. (E3) will not hold exactly for the fitting of the results from actual pulse RTD experiments. The convolution (Eq. E6) of the skewed input shape must be numerically calculated. The actual RTD of the reactor should also include the RTDs in the exit cone and sample line.

\subsubsection{Particle RTD}

For the behavior of particles in the reactor, in general, the following processes need to be accounted for: (1) advection, (2) Brownian diffusion, (3) gravitational settling, (4) growth/shrinkage due to mass transfer from or to the gas phase, and (5) coagulation. The particle number concentration distribution as a function of particle diameter $D_{\mathrm{p}}$ is denoted $n\left(D_{\mathrm{p}}, r, z\right)$. Processes (1)-(4) are related to the penetration efficiency, while the total mass of particles are conserved during the coagulation process with the size distribution being shifted. To discuss the penetration efficiency, coagulation is not included here, which will be further discussed in Sect. 5.1.2

In general, particles undergo both Brownian diffusion in the flow as well as settling under the influence of gravity. Collectively, these processes give rise to particle loss by deposition on the wall during transit through a laminar flow tube reactor. The Brownian diffusion coefficient of a $80 \mathrm{~nm}$ diameter particle is approximately 4 orders of magnitude smaller than that of a typical vapor molecule. Consequently, for typical particle sizes and residence times in the reactor, the Brownian diffusion of particles can be neglected, except in the region very close to the wall, wherein particle uptake at the wall because of diffusion can occur. Gravitational settling of particles in a horizontal tubular flow reactor occurs as particles fall across streamlines and deposit on the lower half of the tube. To assess the effect of gravitational settling of particles, one needs to compare the characteristic settling distance during transit through the reactor, $v_{\mathrm{s}} \tau_{\mathrm{c}, \text { cyld }}$, with the tube radius, $R$, where $v_{\mathrm{s}}$ is the particle settling velocity. Figure 8 shows the size-dependent settling velocity and particle diffusivity for spherical particles. Under typical operating conditions, particles introduced uniformly across the entrance will tend to settle somewhat during transit down the reactor, so this process needs to be accounted for in analyzing particle RTDs. The full equation describing the motion of particles in the horizontal tubular laminar flow under simultaneous diffusion and settling cannot be easily solved. As suggested by the particle-size dependence of settling velocity and diffusivity in Fig. 8, consideration of the two separate regimes, i.e., diffusion and settling, respectively, can simplify the problem. Here we define the diffusion regime as that for particles with diameter $\leq 80 \mathrm{~nm}$ and otherwise for the settling regime. In each regime, we will consider only one process, i.e., either diffusion or settling.

A discussion of the motion of particles in the settling regime is presented in Appendix F. The corresponding RTD (Eq. F4) can be calculated based on the particle trajectories. In the diffusion regime, the settling velocity can be ignored, and Taylor dispersion is not applicable. The RTD of a pulse input can be approximated by the residence time along each streamline (Eq. F7). Since actual particles undergo some degree of radial Brownian diffusion, which is not considered in Eq. (F7), the full RTD should exhibit a broader and smoother profile than that predicted by Eq. (F7) (as simulated by COMSOL; see Sect. 5.2.2).

The penetration efficiency $(\eta)$ for mono-disperse particles can be calculated in their respective regimes. In the settling regime, Eq. (F6) calculates the size-dependent $\eta$. The behavior of particles in the diffusion regime can be calculated by 


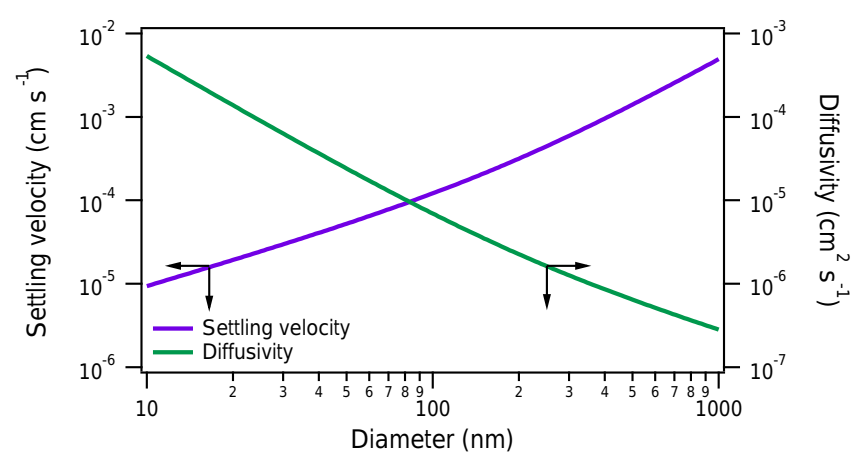

Figure 8. Particle settling velocity and Brownian diffusivity for spherical particles of unit density as a function of particle diameter (Seinfeld and Pandis, 2016).

Eqs. (3) and (4), where removal of particles at the wall is assumed. This is consistent with the boundary condition of the particles in the settling regime.

\section{Results and discussion}

\subsection{Experimental evaluation of penetration efficiency}

The penetration efficiency $(\eta)$ was determined by using a constant input of either gas-phase species $\left(\mathrm{SO}_{2}, \mathrm{O}_{3}\right.$ and $\mathrm{H}_{2} \mathrm{O}_{2}$ ) or polydisperse ammonium sulfate particles through the static mixer or through the flow tube. The RH-dependent penetration efficiency is investigated for both gas-phase species and particles. The results are shown in Fig. 9.

\subsubsection{Vapor molecules}

The $\eta$ of $\mathrm{O}_{3}$ in both the static mixer and the flow tube is constant $(\eta \sim 98 \%)$ over a wide $\mathrm{RH}$ range. $\mathrm{SO}_{2}$ shows no removal by the static mixer, while $\mathrm{H}_{2} \mathrm{O}_{2}$ exhibits a lose of 20 to $40 \%$ in the static mixer. The measured $\eta$ values in the flow tube of all the gas-phase species $\left(\mathrm{O}_{3}, \mathrm{SO}_{2}\right.$ and $\left.\mathrm{H}_{2} \mathrm{O}_{2}\right)$ are essentially $100 \%$ under dry conditions $(\mathrm{RH}<5 \%)$. In the flow tube, the $\eta$ values of both $\mathrm{SO}_{2}$ and $\mathrm{H}_{2} \mathrm{O}_{2}$ decrease with $\mathrm{RH}$. At $\mathrm{RH}=42 \%$, about $70 \%$ of $\mathrm{H}_{2} \mathrm{O}_{2}$ is lost, while at this $\mathrm{RH}$ about $20 \%$ of $\mathrm{SO}_{2}$ is lost. These results show the complexity of the $\eta$ of gas-phase species. The extent of wall deposition of organic vapors in the flow tube reactor requires a comprehensive study and will be addressed in a future publication.

\subsubsection{Particles}

The $\eta$ values for polydisperse ammonium sulfate particles are also investigated at different RH. No RH dependence was found for $\mathrm{RH}<50 \%$, which is below the deliquescence $\mathrm{RH}$ of ammonium sulfate (results not shown). Figure 9c and $\mathrm{d}$ show the measured size distributions before and after the static mixer and the flow tube, as well as the size-dependent penetration efficiency obtained as a ratio. Figure $9 \mathrm{c}$ indicates that about half of the small particles $(<50 \mathrm{~nm})$ are lost in the static mixer, while large particles $(>100 \mathrm{~nm})$ penetrate essentially entirely through the static mixer. This is reasonable since the flow inside the static mixer is laminar $(R e=150)$. The smaller particles diffuse to the static mixer, while the larger ones follow the flow streamline.

The theoretical particle $\eta$ curves under the influence of loss by gravitational settling and diffusion have also been calculated by applying the relevant parameters to Eqs. (4) and (F6) (Fig. 9d). Only the reaction sections were considered in this theoretical calculation (i.e., the inlet and exit cones are excluded). We consider this calculation as a qualitative guideline for $\eta$. Settling velocity and diffusivity of particles are size dependent (Fig. 8), resulting in reduced transmission for very small and large particles due to diffusion loss and gravitational settling, respectively. Both measurements and theory indicate that $\eta$ is maximized at a particle diameter of approximately $100 \mathrm{~nm}$. The measured maximum penetration efficiency is $\sim 80 \%$, indicating a loss of particles, which is likely caused by secondary flow that actively conveys particles closer to the wall. This secondary flow will be discussed in Sect. 5.3. Also, the behavior of particles in the exit cone is difficult to predict and may reflect a certain extent of particle loss.

A numerical coagulation model is used to check the influence of coagulation on particle size distribution. This model uses a PFR framework with an average residence time of $1520 \mathrm{~s}$, which is the measured particle average residence time (Sect. 5.2.2). A unity coagulation efficiency is assumed and no wall deposition of particles. The result is shown in Fig. 10. The comparison indicates that the coagulation process lowers the small particle number, accounting for about half of the missing small particles. The total particle number concentration and average residence time are the two key parameters that impact the coagulation process. Coagulation will have a negligible influence in the case of smaller particle number and shorter residence time. The CPOT typically uses particle number and surface concentrations in the order of magni-

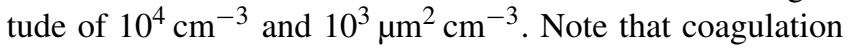
process itself has an impact only on the size distribution not the total particle mass. However, the presence of coagulation may enhance the gravitational settling effect due to the production of larger particles.

\subsection{Experimental evaluation of RTD}

We present here the results of experimental evaluation of the RTD for both vapor molecules and particles. The RTD profiles were determined by introducing a $30 \mathrm{~s}$ pulse of $\mathrm{O}_{3}$ or polydisperse ammonium sulfate particles into the reactor under dry conditions $(\mathrm{RH}<5 \%)$. All experiments were performed at the typical operating flow rate of $2 \mathrm{~L} \mathrm{~min}^{-1}$ in at least triplicate. The average residence time $\left(\tau_{\text {avg }}\right)$ was ob- 

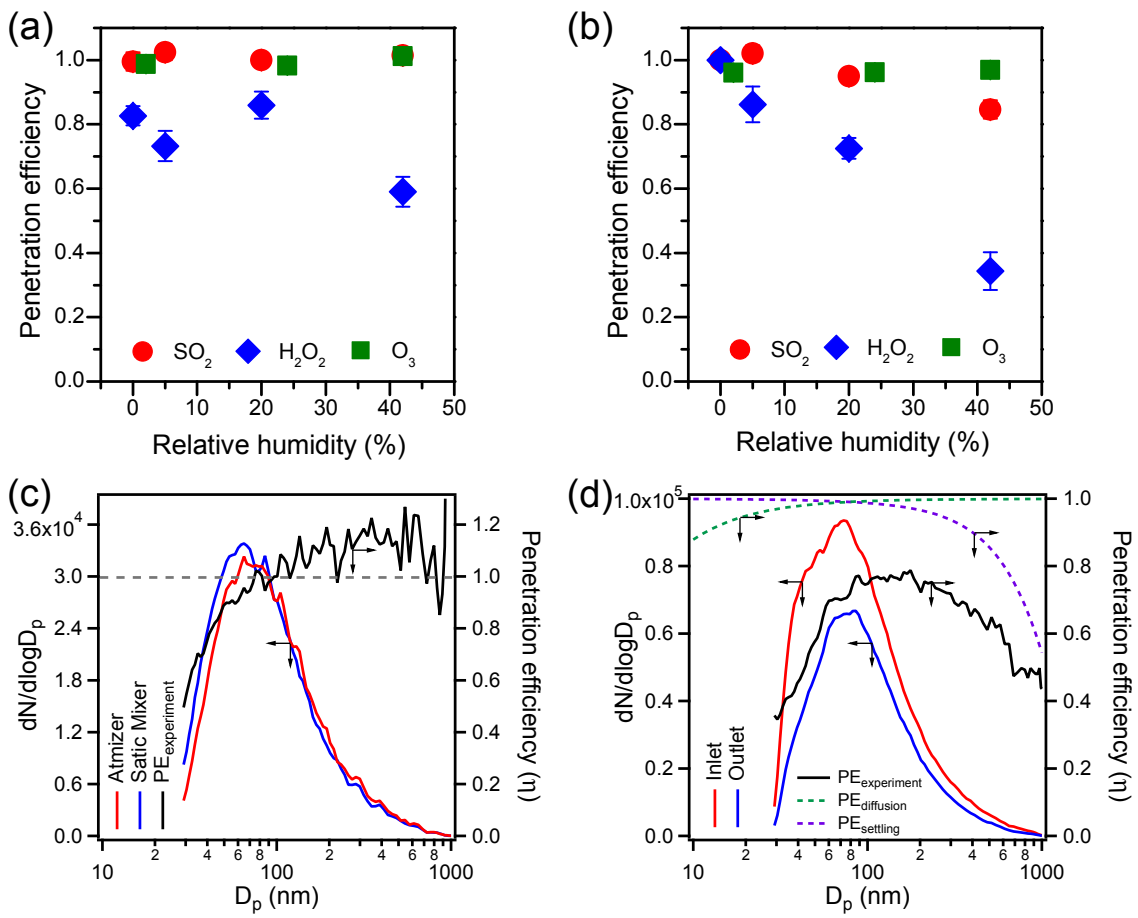

Figure 9. Penetration efficiency $(\eta)$ of gases and particles in the static mixer and the flow tube. (a) Relative-humidity-dependent $\eta$ of $\mathrm{SO}_{2}$, $\mathrm{H}_{2} \mathrm{O}_{2}$ and $\mathrm{O}_{3}$ in the static mixer. (b) Relative-humidity-dependent $\eta$ of $\mathrm{SO}_{2}, \mathrm{H}_{2} \mathrm{O}_{2}$ and $\mathrm{O}_{3}$ in the flow tube. Error bar indicates the measured uncertainty. (c) Measured ammonium sulfate particle size distributions before and after the static mixer, as well as the $\eta$ derived from these measurements. The gray dashed line indicates $\eta=1$, i.e., no particle loss. (d) Measured ammonium sulfate particle size distributions at the inlet and outlet of the flow tube, as well as the $\eta$ derived from these measurements. The calculated $\eta$ with respect to particle diffusion loss (Eq. 4) and gravitational settling (Eq. F6) are indicated by the dashed lines.

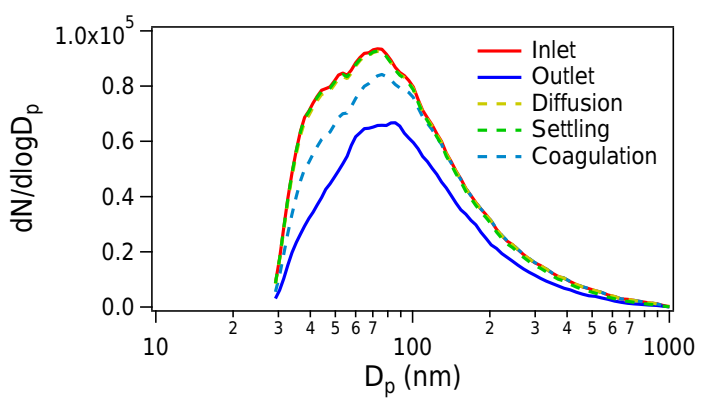

Figure 10. Particle size distributions at the outlet when diffusion, gravitational settling and coagulation processes are coupled separately with the size distribution at the inlet. The measured size distribution at the outlet is plotted as a reference. The coupling of diffusion and gravitational settling with the inlet size distribution is the product of dashed lines and the red line in Fig. 9d. The coagulation process is calculated in a coagulation model, which uses a PFR model with an average residence time of $1520 \mathrm{~s}$ by assuming a unity coagulation efficiency and no wall deposition. The coagulation model input is the size distribution at the inlet.

tained from each RTD profile according to

$\tau_{\text {avg }}=\frac{\Sigma I_{j} t_{j}}{\Sigma I_{j}}$, where $I_{i}$ is the signal recorded at each time step $t_{j}$.

\subsubsection{Vapor molecules}

As noted earlier, a typical value of diffusivity, $1 \times$ $10^{-5} \mathrm{~m}^{2} \mathrm{~s}^{-1}$, is used in COMSOL to predict the gas-phase RTD. Measured and predicted gas-phase RTDs are shown in Fig. 11a. A large discrepancy is observed between the measured and theoretical RTD under presumed isothermal conditions. The predicted gas-phase RTD exhibits a symmetrical distribution centered at approximately $27 \mathrm{~min}$. However, the measured RTD of gas-phase $\mathrm{O}_{3}$ exhibits an asymmetrical feature, somewhat similar to the particle RTD (Fig. 11b). The $\tau_{\text {avg }}$ values obtained from the $\mathrm{O}_{3}$ pulse experiments and simulations are also summarized in Fig. 11a. The measured $\tau_{\mathrm{avg}}$ value of $\mathrm{O}_{3}$ is shorter than predicted by $1.5 \mathrm{~min}$. Potential explanations for measured RTDs are discussed in Sect. 5.3.

\subsubsection{Particles}

A typical value of particle diffusivity, $1 \times 10^{-9} \mathrm{~m}^{2} \mathrm{~s}^{-1}$, corresponding to that of a $\sim 100 \mathrm{~nm}$ diameter particle, is used in COMSOL to predict the RTD. Figure $11 \mathrm{~b}$ compares the measured RTD of polydisperse ammonium sulfate particles to that of the COMSOL simulation. Under isothermal con- 

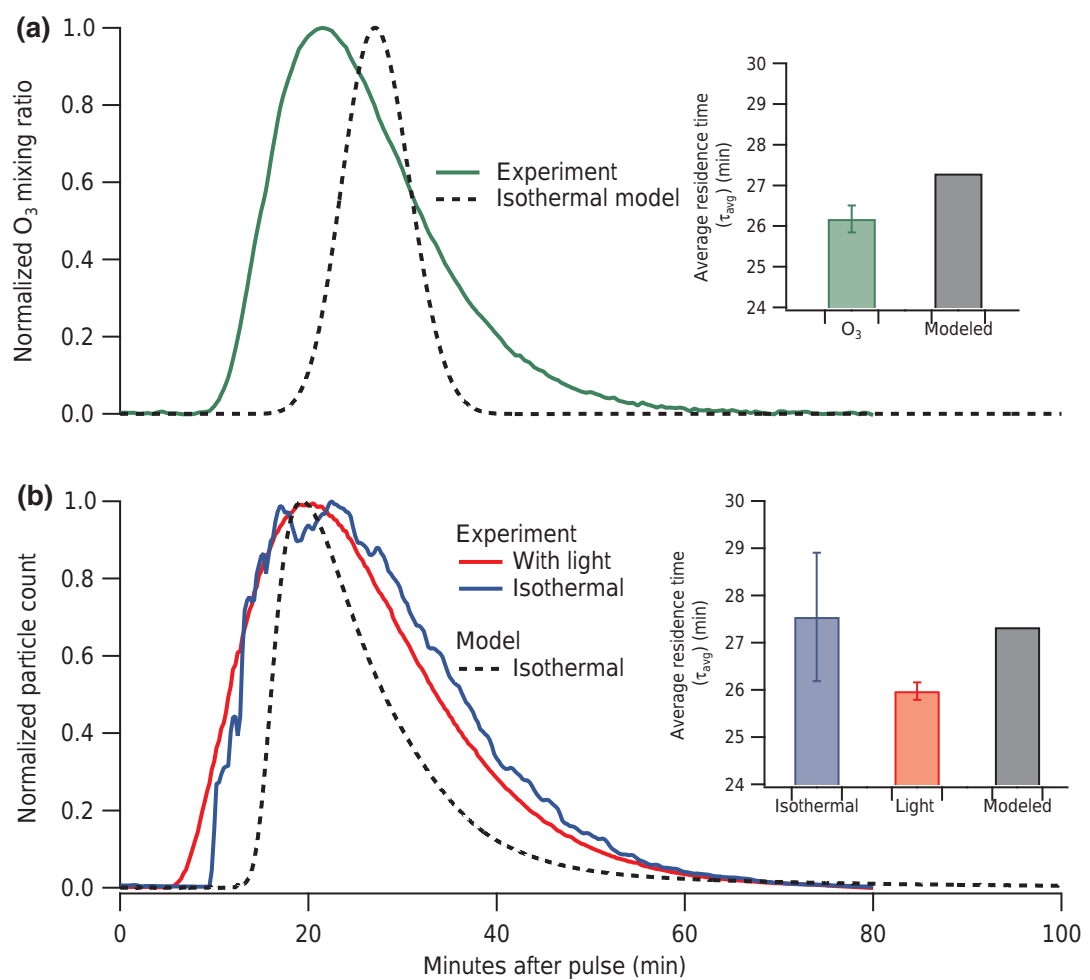

Figure 11. Experimental and COMSOL simulated residence time distributions of (a) $\mathrm{O}_{3}$ vapor molecules and (b) polydisperse ammonium sulfate particles. The diffusivity used in COMSOL for $\mathrm{O}_{3}$ is that for a generic gas-phase species $1 \times 10^{-5} \mathrm{~m}^{2} \mathrm{~s}^{-1}$ and for particles is $1 \times 10^{-9} \mathrm{~m}^{2} \mathrm{~s}^{-1}$ corresponding to a particle size of $\sim 100 \mathrm{~nm}$. The average residence time in each case is compared in the insets as reference.

ditions, the particle RTD exhibits a zigzag feature, which is likely due to the static mixer that may distribute particles somewhat unevenly across streamlines, as can be seen in the velocity profile in Fig. 6a. As laminar flow develops in the reaction section, particles follow their respective streamlines until the exit cone, appearing as the zigzag pattern on the RTD profile. This zigzag feature is absent in the vapor molecule RTD, likely due to the larger diffusivity of vapor molecules. The theoretical RTD of particles in an idealized laminar flow reactor exhibits a sharp peak when the center line first arrives at the exit (Eq. F7). The experimental RTD observed exhibits a rather gradual rise instead of a sharp pulse likely due to the method of introduction (Fig. 6c). Figure $11 \mathrm{~b}$ shows that, under isothermal conditions, the modeled RTD reproduces the shape and the peak time of the observed RTD, and the $\tau_{\text {avg }}$ values also show excellent agreement. However, the modeled RTD appears narrower than that observed. This indicates that particles arrive earlier and remain for a longer time than COMSOL predicts.

Overall, the experimental RTD results of both gas-phase species and particles in the CPOT are essentially comparable to those of present flow reactors (Lambe et al., 2011a), given the arrival time and the width of the peak. This discrepancy of the RTDs between the theoretical laminar flow and the real flow indicates the presence of non-ideal flow in the reactor.

\subsection{Non-ideal flow in the reactor}

The discrepancy between isothermal laminar flow theory and the experimental results can be attributed in part to nonisothermal conditions in the reactor. As noted earlier, the Richardson number (Eq. 1) criterion indicates that a small temperature difference $(\sim 0.007 \mathrm{~K})$ between the bulk and the wall can induce recirculation flows. The measured particle RTDs under isothermal conditions are compared to that obtained under maximum UVA radiation in Fig. 11b. A pronounced difference is that the RTD curve under radiation appears much smoother. The $\tau_{\text {avg }}$ value under irradiation is shortened by $1.5 \mathrm{~min}$ compared to that under isothermal conditions. Given the close agreement between the two RTD profiles, it is unlikely that a recirculation within the tube exists; more likely, the slight non-isothermal condition has created secondary flows that act to mix the tracers both radially and axially.

To further investigate non-isothermal effects, the temperature of the water jacket was raised in a step-wise manner to approach a significant temperature difference between the bulk flow and the wall. The experiments were conducted in the absence of UV radiation. The injected air was at room temperature (approximately $23^{\circ} \mathrm{C}$ ), so a higher water jacket temperature exacerbates the deviation from isothermal conditions. The results of these experiments are shown in 
Fig. 12. The RTD at each temperature is the average of three to four replicates. As shown in Fig. 12a, the RTD at $25^{\circ} \mathrm{C}$ appears indistinguishable from that at quasi-isothermal conditions (the dashed line; we use "quasi-isothermal" here to distinguish from strict isothermal conditions in the model). Particles arrive at the exit cone earlier at higher water jacket temperatures, mirroring the observed discrepancy between the modeled and observed RTD profiles. This trend is clearly illustrated by Fig. 12b, where the arrival time of particles in each experiment is shown as a function of the water jacket temperature. This observation is consistent with the hypothesis that a difference in temperature between the wall and the inlet flow leads to the non-ideal conditions.

Consider that the wall of the reactor is at a constant room temperature as slightly cooler air is introduced into the reactor. Two orthogonal forces interact with each other in the horizontal flow tube when they are of similar orders of magnitude: forced convection by the pressure gradient (horizontal) and buoyancy-induced free convection (vertical). The actual velocity field in this situation is challenging to simulate (Iqbal and Stachiewicz, 1966; Mori and Futagami, 1967; Faris and Viskanta, 1969; Siegwarth et al., 1969). Generally, to satisfy mass conservation, the air close to the wall is warmed and rises along the side wall, inducing a downward flow in the center of the tube, forming two symmetric vortices. Superposition of the primary forced convective and the secondary free convective flows converts the vertical recirculation into spiral motions along the tube. The spiral flow developed in the reaction section plays a similar role as the static mixer in the inlet section. The spiral flow is more easily established if there are hot spots inside, which can be likely, as the sample ports on the reaction sections are not heat-insulated by the water jacket. To quantitatively represent this effect, one can introduce an enhanced isotropic eddy-like diffusivity $\left(\mathcal{D}_{\mathrm{e}}\right)$, a statistical fluid-field-related property.

To verify the presence of the spiral secondary flow in the CPOT, we systematically increased the diffusivity used in the COMSOL simulations. The agreement between simulated and observed RTD improves, as the value of $\mathcal{D}_{\mathrm{e}}$ is increased in the COMSOL simulation, with the optimal agreement achieved when $\mathcal{D}_{\mathrm{e}}=4.5 \times 10^{-4}$ and $6.0 \times 10^{-4} \mathrm{~m}^{2} \mathrm{~s}^{-1}$ for $\mathrm{O}_{3}$ and particles, respectively (Fig. 13). These $\mathcal{D}_{\mathrm{e}}$ values are, respectively, 45 and $6 \times 10^{5}$ times the diffusivity of vapor molecules and particles from the strictly parabolic flow base case (Fig. 11). The vapor molecule RTD (Fig. 13a) no longer exhibits the symmetrical feature of the base case, due to the enhanced Taylor dispersion. The particle RTD (Fig. 13b) is also substantially broadened compared to the base case and exhibits close agreement with the observations. The optimal $\mathcal{D}_{\mathrm{e}}$ values for vapor molecules and particles are similar, suggesting that the molecular diffusion in the CPOT is dominated by the secondary flows. This offers an explanation for the similarity in the observed RTD profiles of $\mathrm{O}_{3}$ and particles, despite orders of magnitude difference in their inherent diffusivity.

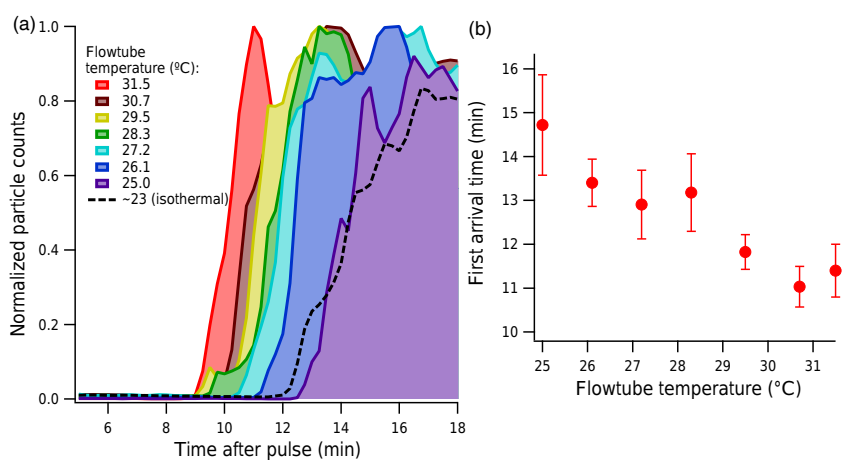

Figure 12. Non-isothermal effects on particle RTD. The water jacket temperature was raised systematically against the room temperature $\left(\sim 23^{\circ} \mathrm{C}\right)$. (a) Normalized ammonium sulfate particle counts recorded at the exit are plotted against time after a pulse is introduced at the inlet. The experiment at each temperature is repeated three to four times. The results from a set of isothermal experiments are also included (dashed line) for reference. (b) Arrival times of the first major peak of each experiment.

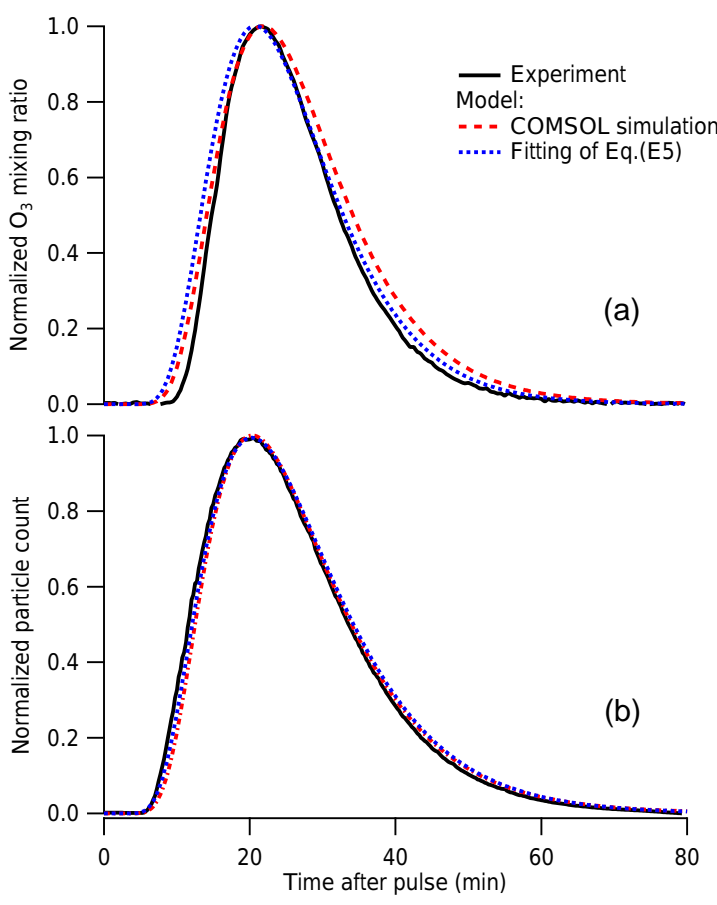

Figure 13. Comparison of experimentally determined RTD of (a) $\mathrm{O}_{3}$ vapor molecules and (b) polydisperse ammonium sulfate particles to optimized simulation results employing an eddy-like diffusivity $\left(\mathcal{D}_{\mathrm{e}}\right)$ in the Taylor dispersion model. The COMSOL simulation employs an optimal $\mathcal{D}_{\mathrm{e}}$ values of $4.5 \times 10^{-4} \mathrm{~m}^{2} \mathrm{~s}^{-1}$ for $\mathrm{O}_{3}$ and $6.0 \times 10^{-4} \mathrm{~m}^{2} \mathrm{~s}^{-1}$ for particles. The fittings of Eq. (E5) employs the same optimal $\mathcal{D}_{\mathrm{e}}$, as well as an optimal average velocity $\left(U_{\text {avg,fit }}\right)$ of $2.1 \times 10^{-3} \mathrm{~m} \mathrm{~s}^{-1}$ and an optimal characteristic residence time $\left(\tau_{\mathrm{c}, \text { cyld,fit }}\right)$ of $1360 \mathrm{~s}$. 
To further evaluate the $\mathcal{D}_{\mathrm{e}}$ values determined from the COMSOL simulations and the hypothesis of secondary flows, one can adopt a separate approach to examine $\mathcal{D}_{\mathrm{e}}$. Given the mixing provided by the static mixer and the conical diffuser, the optimal values of $\mathcal{D}_{\mathrm{e}}$ can be applied in Eq. (E5). The values of $U_{\mathrm{avg}, \text { fit }}$ and $\tau_{\mathrm{c} \text {,cyld,fit }}$ are adjusted to find the best match between Eq. (E5) and the observed RTD profiles. The optimal fitting results are shown in Fig. 13. The fitted average flow velocity $\left(U_{\text {avg,fit }}\right)$ is $2.1 \times 10^{-3} \mathrm{~m} \mathrm{~s}^{-1}$, which results in a characteristic residence time $\tau_{\mathrm{c}, \text { cyld,fit }}$ of $1360 \mathrm{~s}$. This $U_{\text {avg,fit }}$ value agrees well with the designed average velocity $\left(2.0 \times 10^{-3} \mathrm{~m} \mathrm{~s}^{-1}\right)$. This observation again suggests that the non-isothermal secondary-flow-induced eddy-like diffusion dominates the mass transport process in the tube.

Overall, these results highlight the importance of temperature effects in approaching an ideal flow condition in a gasphase laminar flow reactor. Even a small temperature deviation can likely create secondary flows in the flow field that affect both the RTD and the $\tau_{\text {avg }}$ of tracers. It is to be noted that these secondary flows occurring at $R e \cong 20$ should be distinguished from the classic turbulent flow.

\section{Photochemical model}

\subsection{Behavior of species in the models}

The fitted parameters in Sect. 5.3 have been used in the simulation of the photochemical reactions, and the results are shown in Fig. 14. The absorption cross section of $\mathrm{H}_{2} \mathrm{O}_{2}$ increases exponentially towards shorter wavelengths; hence, the $\mathrm{Hg}$ vapor lamp (Fig. 2) is highly efficient in photolyzing $\mathrm{H}_{2} \mathrm{O}_{2}$, whereas the efficiency drops substantially when UVB and UVA lamps are employed (Fig. 14a). The decay of $\mathrm{SO}_{2}$ (Fig. 14b) and the steady-state concentration of the $\mathrm{OH}$ radical (Fig. 14c) follow the photolysis rates of $\mathrm{H}_{2} \mathrm{O}_{2}$ under each type of radiation. The model simulation also confirms that the $\mathrm{OH}$ radical reaches a steady state immediately, with its steady-state concentration, ranging from $\sim 10^{6}$ to $\sim 10^{9}$ molecules $\mathrm{cm}^{-3}$, staying uniform along the entire tube in the presence of a high mixing ratio of $\mathrm{H}_{2} \mathrm{O}_{2}$.

As mentioned in Sect. 2.2, a small amount of the $185 \mathrm{~nm}$ radiation is present in the CPOT when $\mathrm{Hg}$ vapor lamps are equipped. Radiation at $185 \mathrm{~nm}$ generates additional $\mathrm{OH}$ radicals via photolysis of $\mathrm{O}_{2}$ and subsequent reaction between $\mathrm{O}\left({ }^{1} \mathrm{D}\right)$ and $\mathrm{H}_{2} \mathrm{O}$. We have performed control simulations to investigate the relative contribution of the $\mathrm{OH}$ radical generated from this pathway. No $\mathrm{OH}$ was generated in the absence of photolysis of $\mathrm{O}_{2}$ that happens only in the presence of the $185 \mathrm{~nm}$ radiation (data not shown). With the full $\mathrm{Hg}$ vapor emission, even at an $\mathrm{RH}$ as low as $5 \%$, a significant amount of the $\mathrm{OH}$ radical was generated in the absence of $\mathrm{H}_{2} \mathrm{O}_{2}$. The $\mathrm{SO}_{2}$ decay without $\mathrm{H}_{2} \mathrm{O}_{2}$ was approximately half that with $\mathrm{H}_{2} \mathrm{O}_{2}$ (Fig. 14b). The $\mathrm{OH}$ concentration at the end of the reactor reached the same level as the case in which $\mathrm{H}_{2} \mathrm{O}_{2}$ is added (Fig. 14c) but a major difference was observed in the concentration profile of the $\mathrm{OH}$ radical along the tube. Without $\mathrm{H}_{2} \mathrm{O}_{2}$, the $\mathrm{OH}$ concentration increases along the tube, and consequently the decay profiles of $\mathrm{SO}_{2}$ do not follow that of a first-order decay.

Discrepancies were observed in the $\mathrm{H}_{2} \mathrm{O}_{2}$ and $\mathrm{SO}_{2}$ concentration profiles near the inlet and exit of the CPOT between the PFR and AD-PFR models (Fig. 14a and b). These discrepancies arise from the necessary Danckwerts boundary condition, which is more significant at higher oxidation levels. The profiles indicate the effect from the axial dispersion, which arises from the axial mixing induced by secondary flow inside the reactor. The axial dispersion always acts to lower the conversion of the reactant by smoothing the concentration gradient caused by reactions.

\subsection{OH exposure calculation}

The $\mathrm{OH}$ exposure $\left(\mathrm{OH}_{\mathrm{exp}}\right)$ is commonly obtained based on the PFR assumption, using the initial and final concentrations of $\mathrm{SO}_{2}$, i.e., $\left[\mathrm{SO}_{2}\right]_{0}$ and $\left[\mathrm{SO}_{2}\right]_{\tau}$. However, to use the PFR assumption, the effects of radial and axial dispersion need to be addressed. Under the PFR framework, radial diffusion is considered to be rapid, such that the concentration is uniform within a cross section. This assumption can be justified by comparing the radial diffusion timescale $\left(R^{2} / \mathcal{D}\right)$ with the axial convection timescale $(L / U)$, i.e., $R / L P e$, where $P e$ is the Péclet number. A ratio of $\sim 0.01$ with the fitted parameters indicates that radial diffusion is approximately 100 times faster than axial convection and that a uniform cross-section concentration can be expected in the absence of any chemical reactions. The dimensionless group that relates the reaction rate to the diffusion rate is the Damköhler number ( $D a=$ $\frac{k^{\mathrm{I}} R^{2}}{\mathcal{D}}$, where $k^{\mathrm{I}}$ is a first-order reaction rate constant). In the case of the oxidation of $\mathrm{SO}_{2}$ by $\mathrm{OH}, k^{\mathrm{I}}=k_{\mathrm{SO}_{2}+\mathrm{OH}}^{\mathrm{II}}[\mathrm{OH}]$. If $D a \ll 1$, the radial diffusion rate is much faster than the reaction rate, and a uniform cross-section concentration results. In the current chemical system, even with the Hg vapor lamps (the largest $j_{\mathrm{H}_{2} \mathrm{O}_{2}}$ and therefore the most rapid $k^{\mathrm{I}}$ ), the $D a$ value is $0.011 \ll 1$. We conclude that radial diffusion will dominate in the reactor and that the simplified 1-D model framework is valid.

The effect of axial dispersion, in contrast, should be accounted for in interpreting experimental data (Donahue et al., 1996; Howard, 1979). For the first-order reaction system, Howard (1979) showed that the presence of axial dispersion lowers the effective rate constant of a pseudo-first-order reaction by the factor $\left(1-\frac{\mathcal{D} k^{\mathrm{I}}}{U^{2}}\right)$. This correction factor also applies to the $\mathrm{OH}_{\text {exp }}$ calculation.

Starting from the continuity equation, by the assumption of pseudo-first-order reaction $\left(k^{\mathrm{I}}=k^{\mathrm{II}}[\mathrm{OH}]\right)$, the equation governing the steady-state concentration of the tracer down 

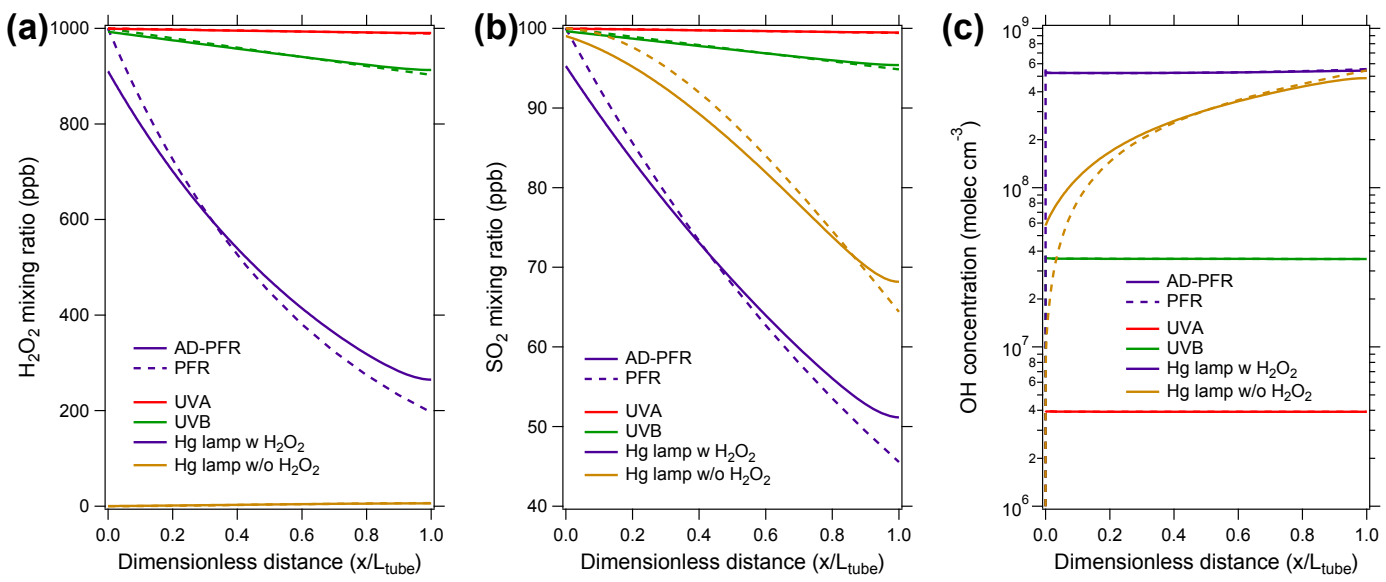

Figure 14. One-dimensional photochemical model using axially dispersed assumption (AD-PFR, solid line) and plug flow assumption (PFR, dashed line). In the simulation, $1 \mathrm{ppm} \mathrm{H}_{2} \mathrm{O}_{2}$ and $100 \mathrm{ppb} \mathrm{SO}_{2}$ at $\mathrm{RH}=5 \%$ and $T=295 \mathrm{~K}$ is used. $\mathrm{Hg}$ vapor (purple), UVB (green) and $\mathrm{UVA}$ (red) lamps at full emission are used to drive the photochemical reactions. (a) Axial profile of $\mathrm{H}_{2} \mathrm{O}_{2}$, (b) axial profile of $\mathrm{SO}_{2}$ and (c) axial profile of $\mathrm{OH}$.

the tube $C(z)$ is

$U \frac{\mathrm{d} C}{\mathrm{~d} z}=\mathcal{D} \frac{\mathrm{d}^{2} C}{\mathrm{~d} z^{2}}-k^{I} C$

Given two appropriate boundary conditions, one can obtain an analytical solution to Eq. (6). In order to use the same initial condition in the AD-PFR model as that in the PFR model, the second-order differential equation can be reduced to a first-order equation through scale analysis. Scaling $C \sim C_{0}$, where $C_{0}$ is the concentration of the tracer in the feed, and $z \sim U / k^{\mathrm{I}}$, Eq. (6) becomes

$f \frac{\mathrm{d}^{2} \widetilde{C}}{\mathrm{~d} \widetilde{z}^{2}}-\frac{\mathrm{d} \widetilde{C}}{\mathrm{~d} \widetilde{z}}-\widetilde{C}=0$,

where $\widetilde{C}=\frac{C}{C_{0}}, \widetilde{z}=\frac{k^{\mathrm{I}}}{U} z$ and $f=\frac{\mathcal{D} k^{\mathrm{I}}}{U^{2}}$. In the CPOT system, typical parameter values are $\mathcal{D} \sim 10^{-4} \mathrm{~m}^{2} \mathrm{~s}^{-1}, k^{\mathrm{I}} \sim$ $10^{-4} \mathrm{~s}^{-1}$ and $U \sim 10^{-3} \mathrm{~ms}^{-1}$; thus $f \sim 10^{-2}$. Due to the relatively small magnitude of $f$, neglecting the second-order derivative term in Eq. (7), the solution of Eq. (7) is

$C(z)=C_{0} \exp \left(-\frac{k^{\mathrm{I}}}{U} z\right)$.

Although $f$ is small, it is not identically zero. To account for the perturbation that occurs due to the small axial dispersion term in Eq. (6), we substitute Eq. (8) into the diffusion term but retain the advection term in derivative form:

$U \frac{\mathrm{d} C}{\mathrm{~d} z}=\mathcal{D}\left(-\frac{k^{\mathrm{I}}}{U}\right)^{2} C-k^{I} C=-k^{\mathrm{I}}(1-f) C$.

Then, substituting $\mathrm{d} t=\frac{\mathrm{d} z}{U}$ and $k^{\mathrm{I}}=k^{\mathrm{II}}[\mathrm{OH}]$ in Eq. (9) one obtains

$\frac{\mathrm{d} C}{\mathrm{~d} t}=-k^{\mathrm{II}}(1-f) C[\mathrm{OH}]$.
In so doing, the diffusion-advection equation has been reduced to a single advection equation, in which the effect of axial dispersion is incorporated into the factor $1-f$.

Integrating Eq. (10), we obtain the $\mathrm{OH}_{\text {exp }}$ expression that accounts for the presence of axial dispersion:

$\mathrm{OH}_{\exp }=\int[\mathrm{OH}] \mathrm{d} t=\frac{1}{k^{\mathrm{II}}(1-f)} \ln \frac{C_{0}}{C_{\tau}}$.

Eq. (11) offers two ways to calculate $\mathrm{OH}_{\text {exp }}$.

The left-hand term is a direct calculation based on the definition of exposure, and the integration incorporates the RTD induced by non-ideal flow conditions. This direct calculation of $\mathrm{OH}_{\text {exp }}$ is most feasible by integrating a mechanism of $\mathrm{OH}-$ tracer chemistry, since $\mathrm{OH}$ is expected to be a function of $t$, which can be simulated. Specifically, if $\mathrm{OH}$ is uniform along the tube, $\int[\mathrm{OH}] \mathrm{d} t=[\mathrm{OH}] \tau_{\mathrm{avg}}$, where $\tau_{\mathrm{avg}}$ is the average residence time. This corresponds to the usual mode of operation. The right-hand expression in Eq. (11) is an indirect calculation, $\mathrm{OH}_{\text {exp }}$, based on the measured concentrations of the tracer at the inlet and the outlet of the reactor, $C_{0}$ and $C_{\tau}$, respectively. Due to the presence of axial dispersion, the actual measured concentration $C_{\tau}$ at the outlet is higher than it would be in the absence of axial dispersion. If no correction for the axial dispersion is applied, the calculated $\mathrm{OH}_{\exp }$ will be lower than it actually is. However, since $f$ is generally small, the increase of $\mathrm{OH}_{\text {exp }}$ due to the presence of axial dispersion is limited to a factor of $\sim f$ (since $\frac{1}{1-f} \approx 1+f$ as $f \ll 1)$. For example, the largest $f=0.05$ occurs in the Hg lamp system. If $f>0.1$, e.g., more significant axial dispersion or much higher $\mathrm{OH}$ level, additional terms should be included in the approximate solution (Eq. 8) and Eq. (10) has to be modified correspondingly. By comparison, in the typical advection system in the absence of axial dispersion, 
$\mathrm{OH}_{\text {exp }}$ is calculated simply as

$\mathrm{OH}_{\exp }=\frac{1}{k^{\mathrm{II}}} \ln \frac{C_{0}}{C_{\tau}}$.

According to Eq. (11), the effect of axial dispersion is enhanced when the $\mathrm{OH}$ oxidation proceeds more rapidly (i.e., at higher $k^{\mathrm{I}}$ values) or the axial dispersion is stronger. There are several ways to estimate the $\mathrm{OH}$ exposure in the axially dispersed flow system. Li et al. (2015) calculate the residence time-dependent $\mathrm{OH}_{\text {exp }}$ first and then couple this relationship with the RTD. Because of the uniform $\mathrm{OH}$ concentration along the tube, the method by Li et al. (2015) and Eq. (12)

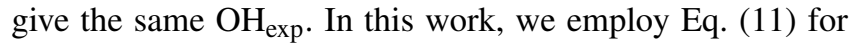
the AD-PFR model and compare the results with those calculated by Eq. (12) for the PFR model. The simulated $\mathrm{OH}_{\text {exp }}$ results are summarized in Table 1, along with their atmospheric equivalent timescale. The results show that the PFR model always gives a higher $\mathrm{OH}_{\text {exp }}$ value and there is an $~ 8-10 \%$ difference between the values calculated by the PFR and ADPFR models, indicating the effect from axial dispersion. Peng et al. (2015) have performed a detailed comparison of $\mathrm{OH}_{\exp }$ calculated with the PFR model, the coupling of RTD with PFR model and the experimental tracer decay method. The authors have recommended using the experimental tracer decay method. For a non-ideal flow reactor, we suggest to use Eq. (11) to account for axial dispersion in the evaluation of $\mathrm{OH}_{\text {exp. }}$

Overall, the current photochemical model indicates that with $\mathrm{H}_{2} \mathrm{O}_{2}$ as the $\mathrm{OH}$ precursor in the absence of $\mathrm{NO}_{x}$, the CPOT can achieve a wide range of steady-state $\mathrm{OH}$ concentrations and $\mathrm{OH}_{\text {exp }}$ that are comparable to the PAM system (Lambe et al., 2011a; Li et al., 2015).

\section{Conclusions}

We report the development of a laminar flow tube reactor for studies of atmospheric VOC oxidation and formation of secondary organic aerosol. The flow tube reactor has been designed to achieve a relatively well-defined flow environment for interpretation of reaction conditions. As has been recognized in existing flow tube reactors, inlet design plays a significant role in establishing the fluid dynamic environment in the reactor. The current design comprises a static mixer followed by a conical diffuser. Computational fluid dynamics simulations demonstrate that this injection scheme introduces flow into the reaction section that avoids flow separation from the wall, assisting a rapid transition to a parabolic profile under idealized, isothermal conditions. Some loss of reactive species, $\mathrm{H}_{2} \mathrm{O}_{2}$, used as an $\mathrm{OH}$ precursor, occurs in the static mixer; however, this loss can be compensated by an increased feed concentration designed to generate the desired $\mathrm{OH}$ level in the reactor.

The fluid dynamics in the reactor was examined experimentally by comparing the penetration efficiency $(\eta)$ and res-
Table 1. Simulated OH exposure under full light emission.

\begin{tabular}{|c|c|c|c|c|}
\hline \multirow[t]{2}{*}{ Lamp type } & \multicolumn{2}{|c|}{$\begin{array}{c}\mathrm{OH}_{\mathrm{exp}}^{\mathrm{a}} \\
\left(\text { molecules cm }{ }^{-3} \mathrm{~s}\right)\end{array}$} & \multicolumn{2}{|c|}{$\begin{array}{l}\text { Atmos. equiv. }{ }^{b} \\
\text { (h) }\end{array}$} \\
\hline & PFR & AD-PFR corr & PFR & AD-PFR ${ }_{\text {corr }}$ \\
\hline $\mathrm{Hg} \mathrm{v}$ & $8.0 \times 10^{11}$ & $7.3 \times 10^{11}$ & 222 & 203 \\
\hline UVB & $5.4 \times 10^{10}$ & $4.9 \times 10^{10}$ & 15 & 13.6 \\
\hline UVA & $6.0 \times 10^{9}$ & $5.4 \times 10^{9}$ & 1.7 & 1.5 \\
\hline
\end{tabular}

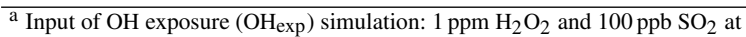
$\mathrm{RH}=5 \%$ and $T=295 \mathrm{~K}\left(\left[\mathrm{H}_{2} \mathrm{O}\right]=1500 \mathrm{ppm}\right)$.

b Atmospheric equivalent (Atmos. equiv.) $\mathrm{OH}_{\exp }$ values are converted to their equivalent hours of $\mathrm{OH}$ exposure in the ambient atmosphere, assuming a typical ambient $\mathrm{OH}$ concentration of $1 \times 10^{6}$ molecules $\mathrm{cm}^{-3}$.

${ }^{\mathrm{c}}$ PFR and AD-PFR corr are calculated by Eqs. (12) and (11), respectively.

idence time distribution of vapor molecules and particles to those predicted under ideal laminar flow conditions. $\mathrm{O}_{3}$ and $\mathrm{SO}_{2}$ molecules exhibit $\sim 100 \%$ transmission in the static mixer. $\mathrm{H}_{2} \mathrm{O}_{2}$ losses in the static mixer are 20 to $40 \%$, increasing as RH increases. Small particles are lost at $\sim 50 \%$ in the static mixer. The penetration efficiency of polydisperse ammonium sulfate particles under dry conditions was measured and compared with theoretical predictions accounting for diffusional deposition and gravitational sedimentation in laminar flow. The penetration efficiency calculated with this theory captures the trend in the two regimes; i.e., in the diffusion regime, the smaller the particles are, the more loss they exhibit, while in the settling regime the larger the particles the more the deposition. A simple coagulation model calculation suggests that the coagulation process accounts for half of the particle number loss over the small size range.

As has been noted in prior studies of flow regime behavior in flow tube reactors, comparison of theoretically predicted and observed RTDs of vapors and particles reveals the importance of small temperature gradients in inducing a departure from the ideal laminar flow. Despite the presence of a temperature-controlled water jacket, the RTD profiles are affected by slightly non-isothermal conditions in the reactor that lead to secondary flows. This conclusion is supported by substantially improved agreement between observed and predicted RTDs when an enhanced eddy-like diffusivity $\left(\mathcal{D}_{\mathrm{e}}\right)$ is employed in the CFD simulations. The best-fit $\left(\mathcal{D}_{\mathrm{e}}\right)$ values, $4.5 \times 10^{-4}$ and $6.0 \times 10^{-4} \mathrm{~m}^{2} \mathrm{~s}^{-1}$ for $\mathrm{O}_{3}$ and particles, respectively, are sufficiently large to indicate that the transport of tracers is likely dominated by secondary flow.

Despite these flow non-idealities, the observations and simulations demonstrate that the combination of the static mixer/conical diffuser allows a radially uniform and axially dispersed flow system to develop within the reactor, useful for quantitative kinetics studies. A 1-D photochemical model is formulated correspondingly. When $\mathrm{H}_{2} \mathrm{O}_{2}$ is employed as the $\mathrm{OH}$ precursor, the model predicts that the $\mathrm{OH}$ concentration is uniform along the whole tube. The extent to which this uniformity depends on the external $\mathrm{OH}$ reactivity, i.e.,

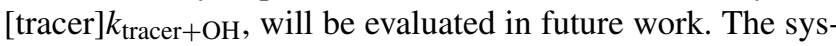


tem can produce a wide range of $\mathrm{OH}_{\mathrm{exp}}$ under different radiation conditions for specific scientific objectives. Future work will focus on detailed studies of secondary organic aerosol formation, with particular attention given to wall interactions of gases and particles.
Data availability. Data presented in this work are available from the authors. 


\section{Appendix A: Determination of photon fluxes}

The irradiance of the three types of lamps from 190 to $850 \mathrm{~nm}\left(E_{e, \lambda}\right)$ was recorded using an Ocean Optics fiber optic spectroradiometer (HR2000CG-UV-NIR). The unit is precalibrated by the manufacturer and is equipped with a $20 \mathrm{~cm}$ long fiber optic cable which can be inserted into the CPOT through one of the sampling ports so that the recorded spectra reflect those inside the CPOT.

The $j_{\mathrm{NO}_{2}}$ values were determined by photolyzing $200 \mathrm{ppb}$ of $\mathrm{NO}_{2}$ that is continuously supplied to the reactor. Mixing ratios of $\mathrm{NO}_{2}, \mathrm{NO}$ and $\mathrm{O}_{3}$ were monitored at the exit cone. Experimental results employing the UVA lamps are shown in Fig. A1. A fraction of $\mathrm{NO}_{2}$ is photolyzed, forming an equivalent amount of $\mathrm{NO}$ and $\mathrm{O}_{3}$. The $j_{\mathrm{NO}_{2}}$ value can be obtained using the photostationary state assumption (Seinfeld and Pandis, 2016):

$j_{\mathrm{NO}_{2}}=\frac{k_{\mathrm{NO}+\mathrm{O}_{3}}\left[\mathrm{O}_{3}\right][\mathrm{NO}]}{\left[\mathrm{NO}_{2}\right]}$,

where $\left[\mathrm{O}_{3}\right],\left[\mathrm{NO}_{2}\right]$ and $[\mathrm{NO}]$ are the concentrations of these three species at photostationary state, respectively. $k_{\mathrm{NO}+\mathrm{O}_{3}}$ is the rate coefficient of the reaction $\mathrm{NO}+\mathrm{O}_{3}$, and a value of $1.9 \times 10^{-14} \mathrm{~cm}^{3} \mathrm{molec}^{-1} \mathrm{~s}^{-1}(298 \mathrm{~K})$ is used here (Seinfeld and Pandis, 2016). The $j_{\mathrm{NO}_{2}}$ value obtained from this experiment is $5.36 \times 10^{-3} \mathrm{~s}^{-1}$. The validity of the photostationary phase was confirmed by solving a simple kinetic model of relevant species (i.e., the mixing ratios of the three species did not further change within the CPOT run time).

The UVA flux was adjusted until we obtained a light intensity $I(\lambda)$ that best represents the observed $j_{\mathrm{NO}_{2}}$. The photolysis rate of species $i, j_{i}$, can be obtained as the integral of its quantum yield $\left(\phi_{i}(\lambda)\right)$, absorption cross section $\left(\sigma_{i}(\lambda)\right)$ and the photon flux $(I(\lambda))$ over wavelengths $\lambda_{1}$ to $\lambda_{2}$ :

$j_{i}=\int_{\lambda_{1}}^{\lambda_{2}} \phi_{i}(\lambda) \sigma_{i}(\lambda) I(\lambda) \mathrm{d} \lambda$.

Determination of $j_{\mathrm{NO}_{2}}$ under the $\mathrm{Hg}$ vapor lamps and UVB lamps, however, was difficult because photolysis of $\mathrm{NO}_{2}$ leads to a net loss of $\mathrm{NO}_{x}$ when these lamps were used (i.e., the photostationary state was not achieved). We suspect the reason is that light with shorter wavelengths created an excess amount of $\mathrm{O}\left({ }^{1} \mathrm{D}\right)$.

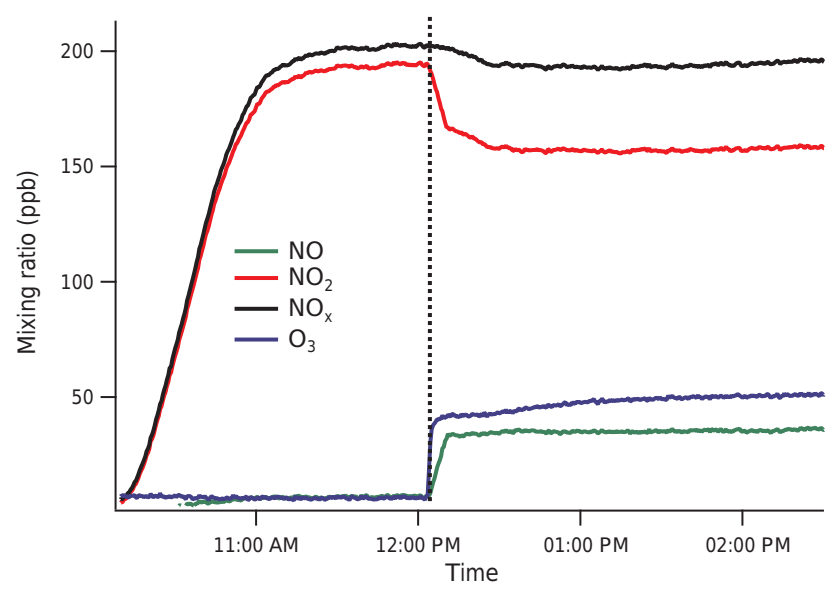

Figure A1. The temporal profiles of $\mathrm{NO}_{2}, \mathrm{NO}, \mathrm{NO}_{x}$ and $\mathrm{O}_{3}$ at the end of the CPOT during a $\mathrm{NO}_{2}$ photolysis experiment. The lamps were turned on at the time indicated by the dashed line.

Alternatively, we determined the fluxes of the $\mathrm{Hg}$ vapor lamp and the UVB lamp by relating the signal strength obtained from these two types of lamp to that from the UVA lamp. We fixed the fiber optics probe at the same position while changing the type of lamps surrounding the CPOT. By doing this, we assume that the ratio between the recorded spectra represents the ratio of their photon fluxes.

The Hg vapor lamp emits wavelength at $185 \mathrm{~nm}$ at an intensity typically less than $1 \%$ of that at $254 \mathrm{~nm}(\mathrm{Li}$ et al., 2015). Direct quantification of $185 \mathrm{~nm}$ light in the CPOT is difficult because the fiber optic spectrometer cannot record radiation with wavelengths shorter than $190 \mathrm{~nm}$. Instead, the intensity of the $185 \mathrm{~nm}$ light can be roughly estimated from $\mathrm{O}_{3}$ formation. Under full emission of the $\mathrm{Hg}$ vapor lamp with $2 \mathrm{~L} \mathrm{~min}^{-1}$ of clean air flowing through, we observe $60 \mathrm{ppb}$ of $\mathrm{O}_{3}$ at the exit cone. Assuming all of $\mathrm{O}_{3}$ has arisen from $\mathrm{O}_{2}$ photolysis, the radiation intensity at $185 \mathrm{~nm}$ can be evaluated based on the Chapman mechanism (Seinfeld and Pandis, 2016) with an average residence time of $1520 \mathrm{~s}$ (Sect. 5.2.2). The intensity of the $185 \mathrm{~nm}$ band is estimated to be $10^{-5}$ that of the $254 \mathrm{~nm}$ band, the majority of which is likely absorbed by the water jacket. 
Appendix B: Photochemical reactions

Table B1. Photolysis reactions in $\mathrm{OH}$ generation.

\begin{tabular}{llrrr}
\hline No. & Reaction & $\begin{array}{r}\text { Photolysis rate } \\
\text { Hg lamps [s }\end{array}$ & $\begin{array}{r}\text { Photolysis rate } \\
\left.\text { UVB lamps [s }{ }^{-1}\right]\end{array}$ & $\begin{array}{r}\text { Photolysis rate } \\
\left.\text { UVA lamps [s }^{-1}\right]\end{array}$ \\
\hline 1 & $\mathrm{H}_{2} \mathrm{O}_{2} \stackrel{h v}{\longrightarrow} 2 \mathrm{OH}$ & $5.48 \times 10^{-4}$ & $3.54 \times 10^{-5}$ & $4.44 \times 10^{-6}$ \\
2 & $\mathrm{O}_{2} \stackrel{h v}{\longrightarrow} 2 \mathrm{O}$ & $1.97 \times 10^{-11}$ & 0 & 0 \\
3 & $\mathrm{O}_{3} \stackrel{h v}{\longrightarrow} \mathrm{O}_{2}+\mathrm{O}\left({ }^{1} \mathrm{D}\right)$ & $7.64 \times 10^{-2}$ & $1.94 \times 10^{-3}$ & $1.53 \times 10^{-5}$ \\
4 & $\mathrm{O}_{3} \stackrel{h v}{\longrightarrow} \mathrm{O}_{2}+\mathrm{O}$ & $8.50 \times 10^{-3}$ & $3.22 \times 10^{-4}$ & $2.61 \times 10^{-5}$ \\
5 & $\mathrm{H}_{2} \mathrm{O} \stackrel{h v}{\longrightarrow} \mathrm{OH}+\mathrm{H}$ & $5.79 \times 10^{-10}$ & 0 & 0 \\
6 & $\mathrm{HO}_{2} \stackrel{h v}{\longrightarrow} \mathrm{OH}+\mathrm{O}\left({ }^{1} \mathrm{D}\right)$ & $2.60 \times 10^{-3}$ & $3.86 \times 10^{-5}$ & $1.76 \times 10^{-7}$ \\
\hline
\end{tabular}

Absorption cross sections and quantum yields come from Burkholder et al. (2015) and IUPAC (http://iupac.pole-ether.fr/). The photon flux was measured in the current study conducted in Caltech. $\mathrm{O}$ refers to $\mathrm{O}\left({ }^{3} \mathrm{P}\right)$. All lamps are at full emission.

Table B2. Reactions in $\mathrm{OH}$ generation and $\mathrm{SO}_{2}$ oxidation.

\begin{tabular}{|c|c|c|c|c|}
\hline No. & Reaction & $\begin{array}{r}\text { Rate constant } \\
{\left[\left(\mathrm{cm}^{3} \text { molecule }^{-1}\right)^{n-1} \mathrm{~s}^{-1}\right]^{\mathrm{a}}}\end{array}$ & $\begin{array}{l}\text { Low-pressure limit } \\
\text { rate constant }\left(k_{0}\right)\end{array}$ & $\begin{array}{l}\text { High-pressure limit } \\
\text { rate constant }\left(k_{\infty}\right)\end{array}$ \\
\hline 1 & $\mathrm{O}^{\mathrm{b}}+\mathrm{O}_{2}+\mathrm{M} \rightarrow \mathrm{O}_{3}+\mathrm{M}$ & $6.0 \times 10^{-34} M(300 / T)^{2.4}$ & & \\
\hline 2 & $\mathrm{O}+\mathrm{O}_{3} \rightarrow 2 \mathrm{O}_{2}$ & $8.0 \times 10^{-12} \exp (-2060 / T)$ & & \\
\hline 3 & $\mathrm{H}+\mathrm{HO}_{2} \rightarrow \mathrm{H}_{2}+\mathrm{O}_{2}$ & $6.9 \times 10^{-12}$ & & \\
\hline 4 & $\mathrm{H}+\mathrm{HO}_{2} \rightarrow 2 \mathrm{OH}$ & $7.2 \times 10^{-11}$ & & \\
\hline 5 & $\mathrm{H}+\mathrm{HO}_{2} \rightarrow \mathrm{H}_{2} \mathrm{O}+\mathrm{O}$ & $1.6 \times 10^{-12}$ & & \\
\hline 6 & $\mathrm{H}+\mathrm{O}_{2}+\mathrm{M} \rightarrow \mathrm{HO}_{2}+\mathrm{M}$ & Eq. $(1)^{\mathrm{c}}$ & $4.4 \times 10^{-32} M(300 / T)^{1.3}$ & $7.5 \times 10^{-11}(300 / T)^{-0.2}$ \\
\hline 7 & $\mathrm{H}+\mathrm{O}_{3} \rightarrow \mathrm{OH}+\mathrm{O}_{2}$ & $1.4 \times 10^{-10} \exp (-470 / T)$ & & \\
\hline 8 & $\mathrm{O}+\mathrm{OH} \rightarrow \mathrm{O}_{2}+\mathrm{H}$ & $1.8 \times 10^{-11} \exp (180 / T)$ & & \\
\hline 9 & $\mathrm{O}+\mathrm{HO}_{2} \rightarrow \mathrm{OH}+\mathrm{O}_{2}$ & $3.0 \times 10^{-11} \exp (200 / T)$ & & \\
\hline 10 & $\mathrm{O}+\mathrm{H}_{2} \mathrm{O}_{2} \rightarrow \mathrm{OH}+\mathrm{HO}_{2}$ & $1.4 \times 10^{-12} \exp (-2000 / T)$ & & \\
\hline 11 & $\mathrm{OH}+\mathrm{H}_{2} \rightarrow \mathrm{H}_{2} \mathrm{O}+\mathrm{H}$ & $2.8 \times 10^{-12} \exp (-1800 / T)$ & & \\
\hline 12 & $2 \mathrm{OH} \rightarrow \mathrm{H}_{2} \mathrm{O}+\mathrm{O}$ & $1.8 \times 10^{-12}$ & & \\
\hline 13 & $2 \mathrm{OH}+\mathrm{M} \rightarrow \mathrm{H}_{2} \mathrm{O}_{2}+\mathrm{M}$ & Eq. (1) & $6.9 \times 10^{-31}(300 / T)$ & $2.6 \times 10^{-11}$ \\
\hline 14 & $\mathrm{OH}+\mathrm{HO}_{2} \rightarrow \mathrm{H}_{2} \mathrm{O}+\mathrm{O}_{2}$ & $4.8 \times 10^{-11} \exp (250 / T)$ & & \\
\hline 15 & $\mathrm{OH}+\mathrm{H}_{2} \mathrm{O}_{2} \rightarrow \mathrm{H}_{2} \mathrm{O}+\mathrm{HO}_{2}$ & $1.8 \times 10^{-12}$ & & \\
\hline 16 & $\mathrm{OH}+\mathrm{O}_{3} \rightarrow \mathrm{HO}_{2}+\mathrm{O}_{2}$ & $\begin{array}{r}1.7 \times 10^{-12} \exp (-940 / T) \\
\left(3.0 \times 10^{-13} \exp (460 / T)\right.\end{array}$ & & \\
\hline 17 & $\mathrm{HO}_{2}+\mathrm{HO}_{2} \rightarrow \mathrm{H}_{2} \mathrm{O}_{2}+\mathrm{O}_{2}$ & $\begin{array}{r}\left.+2.1 \times 10^{-33} \exp (920 / T)\right) \\
\left(1+1.4 \times 10^{-21}\left[\mathrm{H}_{2} \mathrm{O}\right] \exp (2200 / T)\right)\end{array}$ & & \\
\hline 18 & $\mathrm{HO}_{2}+\mathrm{O}_{3} \rightarrow \mathrm{OH}+\mathrm{O}_{2}+\mathrm{O}_{2}$ & $1.0 \times 10^{-14} \exp (-490 / T)$ & & \\
\hline 19 & $\mathrm{O}\left({ }^{1} \mathrm{D}\right)+\mathrm{O}_{2} \rightarrow \mathrm{O}+\mathrm{O}_{2}$ & $3.3 \times 10^{-11} \exp (55 / T)$ & & \\
\hline 20 & $\mathrm{O}\left({ }^{1} \mathrm{D}\right)+\mathrm{N}_{2} \rightarrow \mathrm{O}+\mathrm{N}_{2}$ & $2.15 \times 10^{-11} \exp (110 / T)$ & & \\
\hline 21 & $\mathrm{O}\left({ }^{1} \mathrm{D}\right)+\mathrm{O}_{3} \rightarrow 2 \mathrm{O}_{2}$ & $1.2 \times 10^{-10}$ & & \\
\hline 22 & $\mathrm{O}\left({ }^{1} \mathrm{D}\right)+\mathrm{O}_{3} \rightarrow \mathrm{O}_{2}+2 \mathrm{O}$ & $1.2 \times 10^{-10}$ & & \\
\hline 23 & $\mathrm{O}\left({ }^{1} \mathrm{D}\right)+\mathrm{H}_{2} \rightarrow \mathrm{OH}+\mathrm{H}$ & $1.2 \times 10^{-10}$ & & \\
\hline 24 & $\mathrm{O}\left({ }^{1} \mathrm{D}\right)+\mathrm{H}_{2} \mathrm{O} \rightarrow 2 \mathrm{OH}$ & $1.63 \times 10^{-10} \exp (60 / T)$ & & \\
\hline 25 & $\mathrm{O}+\mathrm{SO}_{2}+\mathrm{M} \rightarrow \mathrm{SO}_{3}+\mathrm{M}$ & Eq. (1) & $5.3 \times 10^{-29}(300 / T)^{4.4}$ & $1.9 \times 10^{-11}(300 / T)^{1.8}$ \\
\hline 26 & $\mathrm{OH}+\mathrm{SO}_{2}+\mathrm{M} \rightarrow \mathrm{HOSO}_{2}+\mathrm{M}$ & Eq. (1) & $3.3 \times 10^{-31}(300 / T)^{4.3}$ & $1.6 \times 10^{-12}$ \\
\hline 27 & $\mathrm{SO}_{3}+2 \mathrm{H}_{2} \mathrm{O} \rightarrow \mathrm{H}_{2} \mathrm{O}+\mathrm{H}_{2} \mathrm{SO}_{4}$ & $8.5 \times 10^{-41} \exp (6540 / T)\left[\mathrm{H}_{2} \mathrm{O}\right]^{2}$ & & \\
\hline 28 & $\mathrm{HOSO} 2+\mathrm{O}_{2} \rightarrow \mathrm{HO}_{2}+\mathrm{SO}_{3}$ & $1.3 \times 10^{-12} \exp (-330 / T)$ & & \\
\hline
\end{tabular}




\section{Appendix C: Danckwerts boundary condition}

At steady state, the simplified 1-D governing equation is

$\mathcal{D}_{\mathrm{e}} \frac{\mathrm{d}^{2} c_{i}}{\mathrm{~d} z^{2}}-U_{\text {avg,fit }} \frac{\mathrm{d} c_{i}}{\mathrm{~d} z}+\sum_{i} R_{i}=0$.

The first term is the axial diffusion, the second term is the convection and the third term contains all the sources and sinks. Equation (C1) has incorporated the Taylor-dispersionderived RTD information. Thus we can solve it as a RTD coupled transport problem. We also employ the Danckwerts boundary condition, which ensures the continuity of the flux:

$$
\begin{aligned}
& \left.U_{\mathrm{avg}, \mathrm{fit}} c_{i}\right|_{0_{-}}=\left.\left[U_{\mathrm{avg}, \mathrm{fit}} c_{i}-\mathcal{D}_{\mathrm{e}} \frac{\mathrm{d} c_{i}}{\mathrm{~d} z}\right]\right|_{0_{+}}, \\
& \left.\frac{\mathrm{d} c_{i}}{\mathrm{~d} z}\right|_{L_{-}}=0
\end{aligned}
$$

In Eq. (C2), $\left.c_{i}\right|_{0_{-}}$is the input concentration, while $\left.c_{i}\right|_{0_{+}}$ is unknown and should be solved. It is this form that determines the discontinuity of the concentration at the inlet. With all the known reactions (Appendix B), one can solve Eqs. (C1) to (C3) numerically. If one wants to add the wall loss terms, assuming a first-order wall loss rate, $k_{\mathrm{w} i}$, the surface-to-volume ratio $(S / V)$ of the reactor should be added, i.e., $\frac{S}{V} k_{\mathrm{w} i} c_{i}$. The $k_{\mathrm{w} i}$ value can be preset if we are interested in the output, or be determined as long as we know the output. The parameters used in these equations are $\mathcal{D}_{\mathrm{e}}=4.5 \times 10^{-4} \mathrm{~m}^{2} \mathrm{~s}^{-1}, U_{\text {avg,fit }}=2.1 \times 10^{-3} \mathrm{~m} \mathrm{~s}^{-1}$, $\tau_{\text {c,cyld,fit }}=1360 \mathrm{~s}$ and $L=U_{\text {avg,fit }} \tau_{\text {c,cyld,fit }}$. As a comparison, a plug flow reactor model runs at the same time, with the only parameter as $\tau_{\mathrm{avg}}=1520 \mathrm{~s}$.

\section{Appendix D: Diffusional loss in a laminar cylindrical tube}

The full conservation equation for gas-phase species $i$, $c_{i}(t, r, z)$, is

$\frac{\partial c_{i}}{\partial t}+v_{z}(r) \frac{\partial c_{i}}{\partial z}=\mathcal{D}_{i}\left[\frac{1}{r} \frac{\partial}{\partial r}\left(r \frac{\partial c_{i}}{\partial r}\right)+\frac{\partial^{2} c_{i}}{\partial z^{2}}\right]+P_{i}-S_{i}$

where $\mathcal{D}_{i}$ is the molecular diffusivity of species $i$ in air, and $P_{i}$ and $S_{i}$ are the rates of generation and consumption of species $i$, by chemical reaction and gas-particle partitioning, respectively. A typical order of magnitude estimate of the molecular diffusion coefficient for vapor molecules in air is $\sim 10^{-5} \mathrm{~m}^{2} \mathrm{~s}^{-1}$. Under conditions typical of the operation of the flow tube reactor, the magnitude of the axial molecular diffusion term in Eq. (D1) is small relative to that of the other terms in the equation and may be neglected. Davis (2008) gives a thorough discussion on the analytical solution for this system that is at steady state. Without any generation and consumption of species $i$, Eq. (D1) becomes

$v_{z}(r) \frac{\partial c_{i}}{\partial z}=\mathcal{D}_{i}\left[\frac{1}{r} \frac{\partial}{\partial r}\left(r \frac{\partial c_{i}}{\partial r}\right)\right]$.

Equation (D2) is subject to a boundary condition at the reactor entrance, $z=0$ :

$c_{i}(r, 0)=c_{i 0}$,

where a uniform concentration $c_{i 0}$ is assumed at the inlet of the reactor, and the symmetry condition at the centerline of the reactor, $r=0$ :

$\frac{\partial c_{i}}{\partial r}(0, z)=0$

A general boundary condition at the reactor wall allows for the possible deposition of species $i$ on the wall, is

$\mathcal{D}_{i} \frac{\partial c_{i}}{\partial r}(R, z)=-k_{\mathrm{w} i} c_{i}$

where $k_{\mathrm{w} i}$ is a first-order wall deposition coefficient for species $i . k_{\mathrm{w} i}$ can be expressed in terms of the uptake coefficient for species $i, \gamma_{i}$, as $k_{\mathrm{w} i}=\frac{1}{4} \gamma_{i} \omega_{i}$, where $\omega_{i}$ is the mean molecular speed of species $i$. Either $k_{\mathrm{w} i}$ or $\gamma_{i}$ must be determined experimentally. If no uptake of species $i$ occurs at the wall, then $k_{\mathrm{w} i}=0$.

\section{Appendix E: Taylor dispersion-based RTD}

By cross-section averaging of Eq. (D1) (without sources and sinks), the average concentration at any cross section obeys

$\frac{\partial\left\langle c_{i}\right\rangle}{\partial t}+U_{\mathrm{avg}} \frac{\partial\left\langle c_{i}\right\rangle}{\partial z}=\mathcal{D}_{\mathrm{eff}, i} \frac{\partial^{2}\left\langle c_{i}\right\rangle}{\partial z^{2}}$,

where $\mathcal{D}_{\text {eff, } i}=\mathcal{D}_{i}\left(1+\frac{P e^{2}}{192}\right)$, which accounts for the convective enhancement in diffusivity (Aris, 1956), where $P e$, the Péclet number, is $\frac{2 R U_{\text {avg }}}{\mathcal{D}_{i}}$.

The solution of Eq. (E1) for a pulse input at the entrance to the reactor, of $N_{0}$ moles over the cross-section area $A$ of the tube, is

$\left\langle c_{i}\right\rangle(t, z)=\frac{1}{\sqrt{4 \pi \mathcal{D}_{\mathrm{eff}, i} t}} \frac{N_{0}}{A} \exp \left[-\frac{\left(z-U_{\mathrm{avg}} t\right)^{2}}{4 \mathcal{D}_{\mathrm{eff}, i} t}\right]$.

The RTD of the diffusive species in the flow tube, i.e., at $z=L_{\text {cyld }}$, is

$\left\langle c_{i}\right\rangle\left(t, L_{\text {cyld }}\right)=\frac{1}{\sqrt{4 \pi \widetilde{\mathcal{D}}_{\text {eff }, i} \widetilde{t}}} \frac{N_{0}}{V} \exp \left[-\frac{(1-\widetilde{t})^{2}}{4 \widetilde{\mathcal{D}}_{\text {eff }, i} \widetilde{t}}\right]$,

where $V$ is the volume of the tube, $\widetilde{\mathcal{D}}_{\text {eff }, i}=\frac{\mathcal{D}_{\text {eff }, i}}{\tau_{\mathrm{c}, \text { cyld }} U_{\text {avg }}^{2}}$ and $\widetilde{t}=$ $\frac{t}{\tau_{\mathrm{c}, \text { cyld }}}$. 
For a pulse input, of finite duration $t_{0}$,

$\left\langle c_{i}\right\rangle(t, z=0)= \begin{cases}\frac{N_{0}}{A U_{\text {avg }} t_{0}} & 0 \leq t \leq t_{0} \\ 0 & t>t_{0} .\end{cases}$

The RTD at $z=L_{\text {cyld }}$ is

$$
\begin{aligned}
& \left\langle c_{i}\right\rangle\left(t, L_{\text {cyld }}\right)= \\
& \frac{N_{0}}{2 V}\left[\operatorname{erf}\left(\frac{1-\widetilde{t}}{\sqrt{4 \widetilde{\mathcal{D}}_{\mathrm{eff}, i} \widetilde{t}}}\right)-\operatorname{erf}\left(\frac{1-\widetilde{t}-\widetilde{t_{0}}}{\sqrt{4 \widetilde{\mathcal{D}}_{\mathrm{eff}, i} \widetilde{t}}}\right)\right],
\end{aligned}
$$

where $\operatorname{erf}(x)=\frac{2}{\sqrt{\pi}} \int_{0}^{x} \exp \left(-\eta^{2}\right) \mathrm{d} \eta$ and $\widetilde{t_{0}}=\frac{t_{0}}{\tau_{c, \text { cyld }}}$. More generally, by transforming $t=-\frac{z}{U_{\text {avg }}}=-\frac{z}{L_{\text {cyld }}} \frac{L_{\text {cyld }}}{U_{\text {avg }}}=$ $-\tilde{z} \tau_{\mathrm{c}, \text { cyld }}$, where $\tilde{z}=\frac{z}{L_{\text {cyld }}}$, the RTD for a non-ideal pulse input $f(t)$ (e.g., the solid profile in Fig. 6c) is in the form of

$$
\begin{aligned}
\left\langle c_{i}\right\rangle\left(t, L_{\text {cyld }}\right)= & \frac{1}{\sqrt{4 \pi \widetilde{\mathcal{D}}_{\mathrm{eff}, i} \widetilde{t}}} \frac{N_{0}}{V} \int_{-\infty}^{+\infty} f\left(-\widetilde{z} \tau_{\mathrm{c}, \text { cyld }}\right) \\
& \exp \left[-\frac{(1-\widetilde{t}-\widetilde{z})^{2}}{4 \widetilde{\mathcal{D}}_{\mathrm{eff}, i} \tilde{t}}\right] \mathrm{d} \widetilde{z},
\end{aligned}
$$

where $\widetilde{\mathcal{D}}_{\text {eff }, i}$ and $\widetilde{t}$ are defined as in Eqs. (E3) and (E5).

\section{Appendix F：Particle size-dependent RTDs}

Figure 8 can be used to define two separate regimes of particle behavior, i.e., settling regime (diameter larger than $80 \mathrm{~nm}$ ) and diffusion regime (otherwise).

While cylindrical coordinates are usually employed in a flow tube reactor, it will prove to be advantageous to use a Cartesian coordinate framework for the numerical simulation of particle settling in horizontal laminar flow in a tubular geometry. In the settling regime, particle motion in a horizontal tubular laminar flow is governed by the following differential equations for particle position, $(x(t), y(t), z(t))$, in a Cartesian coordinate system (with origin at the center of the tube at $t=0$, as shown in Fig. F1):

$\frac{\mathrm{d} x}{\mathrm{~d} t}=0$,

$$
\begin{aligned}
& \frac{\mathrm{d} y}{\mathrm{~d} t}=-v_{y}\left(D_{\mathrm{p}}\right)=-v_{\mathrm{s}}\left(D_{\mathrm{p}}\right), \\
& \frac{\mathrm{d} z}{\mathrm{~d} t}=v_{z}(x, y)=U_{\max }\left(1-\frac{x^{2}+y^{2}}{R^{2}}\right) .
\end{aligned}
$$

Given an initial particle position, $x(0)=x_{0}, y(0)=y_{0}$, $z(0)=z_{0}$, this set of equations can be solved either numerically or analytically. Examples of the numerical simulation of particle trajectories are shown in Fig. F1.

The analytical solution of Eqs. (F1)-(F3) for the time $\tau$ that a particle resides in the flow is

$\widetilde{t}^{3}-2 \widetilde{y} \tilde{t}^{2}-\left(1-\widetilde{x}^{2}-\widetilde{y}^{2}\right) \widetilde{t}+\frac{t_{1}}{t_{2}}=0$,

where $\tilde{x}=x_{0} / R, \tilde{y}=y_{0} / R, t_{1}=L_{\text {cyld }} / U_{\max }, t_{2}=R / v_{\mathrm{s}}$ and $\tilde{t}=t / t_{2} . \tilde{x}$ and $\tilde{y}$ are subject to the condition

$\tilde{y}\left(1-\widetilde{x}^{2}\right)-\frac{1}{3} \widetilde{y}^{3}-\frac{t_{1}}{t_{2}}+\frac{2}{3}\left(1-\widetilde{x}^{2}\right)^{\frac{3}{2}} \leq \widetilde{x}^{2}+\widetilde{y}^{2} \leq 1$.

The integral over this closed space leads to the penetration efficiency $\eta$ for non-diffusive monodisperse particles:

$\eta=$

$$
\frac{2}{\pi}\left(-2 \epsilon \sqrt{1-\epsilon^{\frac{2}{3}}}+\epsilon^{\frac{1}{3}} \sqrt{1-\epsilon^{\frac{2}{3}}}+\arcsin \sqrt{1-\epsilon^{\frac{2}{3}}}\right),
$$

where $\epsilon=\frac{3 t_{1}}{4 t_{2}}$ and the implicit condition here is that $\epsilon \leq 1$, i.e., $v_{\mathrm{s}} \leq \frac{4 R}{3 L_{\text {cyld }}} U_{\max }$, otherwise $\eta=0$. Calculated theoretical RTD and $\eta$ are shown in Fig. F2.

The RTD of non-diffusing materials along each streamline for a pulse input is

$\langle n\rangle\left(t, L_{\text {cyld }}\right)= \begin{cases}0 & 0 \leq t<t_{1} \\ \frac{2 N_{0} t_{1}^{2}}{A U_{\text {avg }} t^{3}} & t \geq t_{1},\end{cases}$

where $N_{0}$ is the total input quantity of the pulse, the same as defined in Appendix E. 


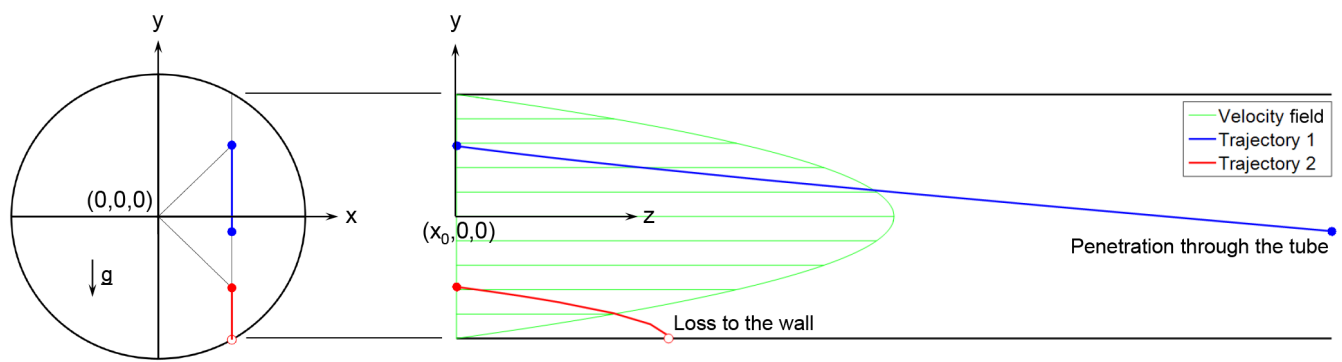

Figure F1. Particle trajectories in a vertical plane in a laminar flow tube. Particles are of the same size and are subject to gravitational settling and fluid advection. The Cartesian coordinate framework is indicated. Two different cases are shown: blue particles are those that can successfully penetrate through the tube, while red particles eventually deposit on the tube wall.
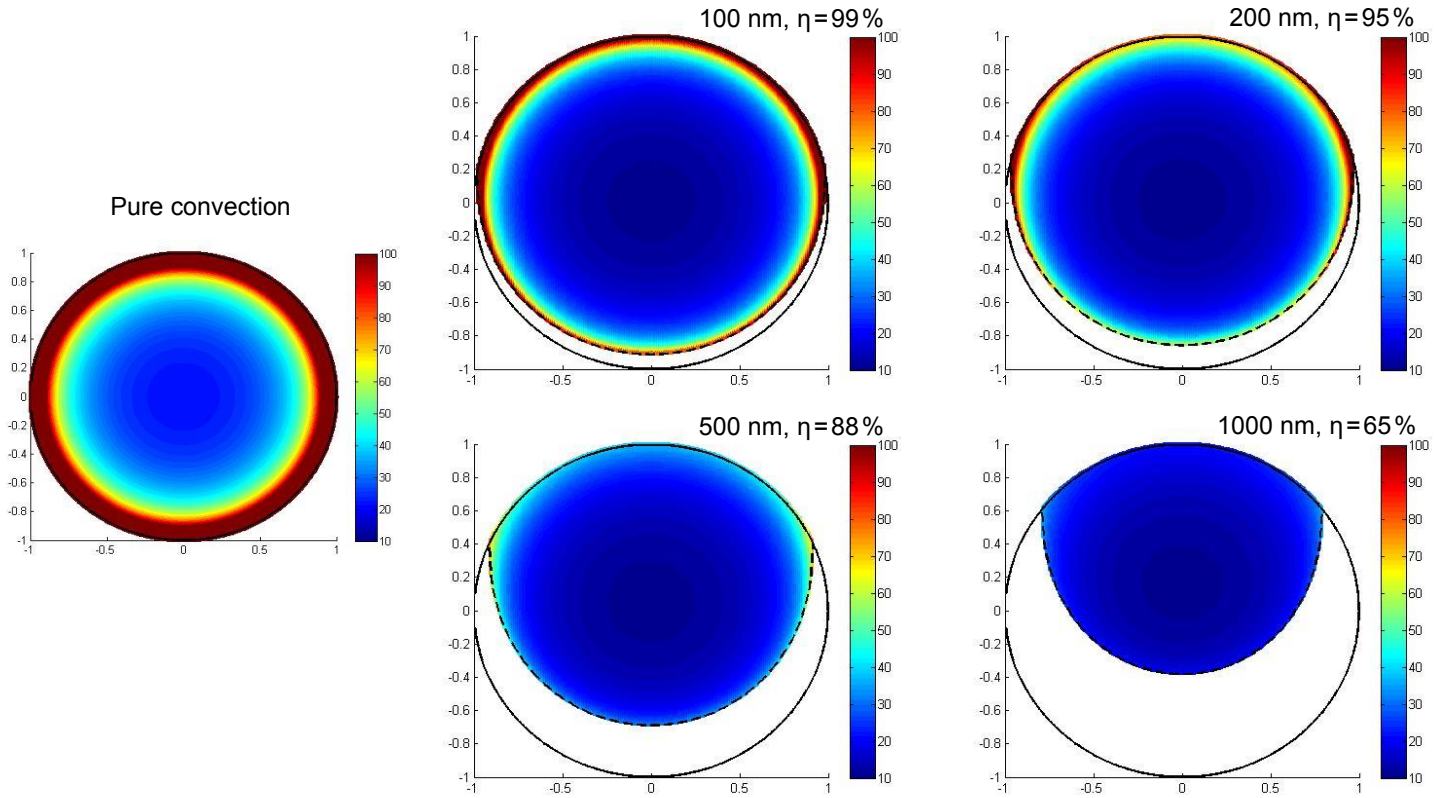

Figure F2. Theoretical residence time distribution (Eq. F4) and penetration efficiency (Eq. F6) of particles with different diameters in a horizontal flow tube. Only gravitational settling and convection are considered. The simulation assumes a uniform distribution of monodisperse particles at the entrance of a well-developed laminar flow with no interaction between particles. Each point corresponds to the residence time and the initial position of the particle. The color bar indicates the residence time (min). The open space between the dashed curve and the tube wall indicates the region in which particles have deposited on the tube wall $(\eta=0 \%)$. The residence time of purely convective, non-diffusing particles (Eq. F7) is shown for reference. 


\section{Appendix G: List of symbols}

\begin{tabular}{lll} 
Symbol & Meaning & Unit \\
\hline$A$ & cross section of the reactor & $\mathrm{m}^{2}$ \\
$c$ & concentration & $\mathrm{mol} \mathrm{m}^{-3}$ \\
$D$ & reactor diameter & $\mathrm{m}$ \\
$D_{\mathrm{p}}$ & particle diameter & $\mathrm{nm}$ \\
$\mathcal{D}$ & diffusivity & $\mathrm{m}^{2} \mathrm{~s}^{-1}$ \\
$g$ & gravitational acceleration & $\mathrm{m} \mathrm{s}^{-2}$ \\
$k_{\mathrm{W}}$ & mass transport coefficient to the wall & $\mathrm{m} \mathrm{s}^{-1}$ \\
$L$ & length of the reactor & $\mathrm{m}$ \\
$n$ & particle number concentration & $\mathrm{cm}^{-3}$ \\
$N_{0}$ & total moles or number of the pulse input & $\mathrm{mole} \mathrm{or} \mathrm{number}^{-1}$ \\
$P$ & generation rate of species & $\mathrm{molec} \mathrm{cm}^{-3} \mathrm{~s}^{-1}$ \\
$R$ & radius of the reactor & $\mathrm{m}$ \\
$S$ & consumption rate of species & $\mathrm{molec} \mathrm{cm}^{-3} \mathrm{~s}^{-1}$ \\
$t_{0}$ & duration & $\mathrm{s}$ \\
$T$ & temperature & $\mathrm{K}$ \\
$U$ & characteristic velocity of the fluid & $\mathrm{m} \mathrm{s}^{-1}$ \\
$v$ & velocity & $\mathrm{m} \mathrm{s}^{-1}$ \\
$V$ & volume of the reactor & $\mathrm{m}^{3}$ \\
$Q$ & volumetric flow rate & $\mathrm{m}^{3} \mathrm{~s}^{-1}$ \\
\hline Greek & & \\
\hline$\beta$ & thermal expansion coefficient of fluid & $\mathrm{K}^{-1}$ \\
$\mu$ & viscosity of the fluid & $\mathrm{kg} \mathrm{m}^{-1} \mathrm{~s}^{-1}$ \\
$\nu$ & kinematic viscosity & $\mathrm{m}^{2} \mathrm{~s}^{-1}$ \\
$\rho$ & density of fluid & $\mathrm{kg} \mathrm{m}^{-3}$ \\
$\theta$ & angle of the cone & $\mathrm{s}$ \\
$\tau$ & residence time & $\mathrm{m} \mathrm{s}^{-1}$ \\
$\omega$ & mean molecular speed &
\end{tabular}

Note: some of the symbols appear in Appendix D-F. 
Appendix H: List of dimensionless numbers and subscripts

\begin{tabular}{lll} 
Symbol & Name & Expression \\
\hline Greek & & \\
\hline$\gamma$ & uptake coefficient & \\
$\eta$ & penetration efficiency & \\
$\epsilon$ & ratio of timescale of convection to that of settling & $3 L_{\text {cyld }} v_{\mathrm{s}} / 4 R U_{\text {max }}$ \\
$\xi$ & dimensionless length & $\pi \mathcal{D} L_{\text {cyld }} / Q$ \\
\hline Dimensionless groups & \\
\hline$G r$ & Grashof number & $g \beta D^{3} \Delta T / \nu^{2}$ \\
$P e$ & Péclet number & $2 R U_{\text {avg }} / \mathcal{D}_{i}$ \\
$R e$ & Reynolds number & $\rho U_{\text {avg }} D / \mu$ \\
$R i$ & Richardson number & $G r / R e^{2}$ \\
\hline Subscripts & \\
\hline c & characteristic value & \\
cyld & cylindrical tube & \\
e & eddy-like & \\
fit & fitted result & \\
$i$ & species & \\
$j$ & time step & \\
s & settling & \\
avg & average value & \\
eff & effective value \\
entr & entrance & \\
in & inlet & \\
max & maximum value & \\
out & outlet & \\
$r$ & $r$ component in cylindrical framework & \\
$x$ & $x$ component in Cartesian framework & \\
$y$ & $y$ component in Cartesian framework & \\
$z$ & $z$ component in Cartesian or cylindrical framework & \\
\hline Superser & \\
\hline
\end{tabular}

\begin{tabular}{ll}
\hline \multicolumn{2}{l}{ Superscripts } \\
\hline I & first-order reaction rate \\
II & second-order reaction rate \\
\hline \multicolumn{2}{l}{ Overbar } \\
\hline$\sim$
\end{tabular}

Note: some of the symbols appear in Appendix D-F. 
Competing interests. The authors declare that they have no conflict of interest.

Acknowledgements. We gratefully acknowledge a generous gift by Christine and Dwight Landis to support the construction of this reactor. We also thank Paul Wennberg for useful discussions and for offering laboratory supplies. This work was supported by National Science Foundation grant AGS-1523500. Ran Zhao was supported by the Natural Science and Engineering Research Council of Canada.

Edited by: H. Harder

Reviewed by: A. Lambe and four anonymous referees

\section{References}

Aris, R.: On the dispersion of a solute in a fluid flowing through a tube, P. Roy. Soc. Lond. A Mat., 235, 67-77, 1956.

Bates, K. H., Crounse, J. D., St Clair, J. M., Bennett, N. B., Nguyen, T. B., Seinfeld, J. H., Stoltz, B. M., and Wennberg, P. O.: Gas Phase Production and Loss of Isoprene Epoxydiols, J. Phys. Chem. A, 118, 1237-1246, 2014.

Bates, K. H., Nguyen, T. B., Teng, A. P., Crounse, J. D., Kjaergaard, H. G., Stoltz, B. M., Seinfeld, J. H., and Wennberg, P. O.: Production and Fate of C-4 Dihydroxycarbonyl Compounds from Isoprene Oxidation, J. Phys. Chem. A, 120, 106-117, 2016.

Beder, E. C., Bass, C. D., and Shackleford, W. L.: Transmissivity and Absorption of Fused Quartz Between $0.22 \mu$ and $3.5 \mu$ from Room Temperature to $1500^{\circ} \mathrm{C}$, Appl. Optics, 10, 2263-2268, 1971.

Bird, R. B., Stewart, W. E., and Lightfoot, E. N.: Transport Phenomena (revised), 2 edn., John Wiley \& Sons Inc., New York, USA, 2007.

Bonn, B., Schuster, G., and Moortgat, G. K.: Influence of Water Vapor on the Process of New Particle Formation during Monoterpene Ozonolysis, J. Phys. Chem. A, 106, 2869-2881, 2002.

Bruns, E. A., El Haddad, I., Keller, A., Klein, F., Kumar, N. K., Pieber, S. M., Corbin, J. C., Slowik, J. G., Brune, W. H., Baltensperger, U., and Prévôt, A. S. H.: Inter-comparison of laboratory smog chamber and flow reactor systems on organic aerosol yield and composition, Atmos. Meas. Tech., 8, 23152332, doi:10.5194/amt-8-2315-2015, 2015.

Burkholder, J. B., Sander, S. P., Abbatt, J., Barker, J. R., Huie, R. E., Kolb, C. E., Kurylo, M. J., Orkin, V. L., Wilmouth, D. M., and Wine, P. H.: Chemical Kinetics and Photochemical Data for Use in Atmospheric Studies, Evaluation No. 18, JPL Publication 1510, Jet Propulsion Laboratory, Pasadena, USA, 2015.

Chen, S., Brune, W. H., Lambe, A. T., Davidovits, P., and Onasch, T. B.: Modeling organic aerosol from the oxidation of $\alpha$-pinene in a Potential Aerosol Mass (PAM) chamber, Atmos. Chem. Phys., 13, 5017-5031, doi:10.5194/acp-13-5017-2013, 2013.

Crounse, J. D., McKinney, K. A., Kwan, A. J., and Wennberg, P. O.: Measurement of Gas-Phase Hydroperoxides by Chemical Ionization Mass Spectrometry, Anal. Chem., 78, 6726-6732, 2006.

Davis, E. J.: Interpretation of uptake coefficient data obtained with flow tubes, J. Phys. Chem. A, 112, 1922-1932, 2008.
Davis, M. E. and Davis, R. J.: Fundamentals of Chemical Reaction Engineering, Courier Corporation, New York, USA, 2003.

Donahue, N. M., Clarke, J. S., Demerjian, K. L., and Anderson, J. G.: Free-Radical Kinetics at High Pressure: A Mathematical Analysis of the Flow Reactor, J. Phys. Chem., 100, 5821-5838, 1996.

Ezell, M. J., Johnson, S. N., Yu, Y., Perraud, V., Bruns, E. A., Alexander, M. L., Zelenyuk, A., Dabdub, D., and FinlaysonPitts, B. J.: A new aerosol flow system for photochemical and thermal studies of tropospheric aerosols, Aerosol Sci. Tech., 44, 329-338, 2010.

Faris, G. N. and Viskanta, R.: An analysis of laminar combined forced and free convection heat transfer in a horizontal tube, Int. J. Heat Mass Tran., 12, 1295-1309, 1969.

Fried, E. and Idel'chik, I. E.: Flow Resistance: A Design Guide for Engineers, Hemisphere Pub. Co., New York, USA, 1989.

Fuchs, N. A.: The Mechanics of Aerosols, Pergamon, New York, USA, 1964.

George, I. J., Vlasenko, A., Slowik, J. G., Broekhuizen, K., and Abbatt, J. P. D.: Heterogeneous oxidation of saturated organic aerosols by hydroxyl radicals: uptake kinetics, condensed-phase products, and particle size change, Atmos. Chem. Phys., 7, 41874201, doi:10.5194/acp-7-4187-2007, 2007.

Gormley, P. G. and Kennedy, M.: Diffusion from a stream flowing through a cylindrical tube, P. Roy. Irish Acad. A, 52, 163-169, 1948.

Grayson, J. W., Song, M., Sellier, M., and Bertram, A. K.: Validation of the poke-flow technique combined with simulations of fluid flow for determining viscosities in samples with small volumes and high viscosities, Atmos. Meas. Tech., 8, 2463-2472, doi:10.5194/amt-8-2463-2015, 2015.

Hodas, N., Zuend, A., Mui, W., Flagan, R. C., and Seinfeld, J. H.: Influence of particle-phase state on the hygroscopic behavior of mixed organic-inorganic aerosols, Atmos. Chem. Phys., 15, 5027-5045, doi:10.5194/acp-15-5027-2015, 2015.

Holman, J. P.: Heat Transfer, 10 edn., McGraw-Hill, New York, USA, 2010.

Howard, C. J.: Kinetic measurements using flow tubes, J. Phys. Chem., 83, 3-9, 1979.

Iqbal, M. and Stachiewicz, J. W.: Influence of tube orientation on combined free and forced laminar convection heat transfer, J. Heat Transf., 88, 109-116, 1966.

Jonsson, A. M., Hallquist, M., and Ljungström, E.: Influence of $\mathrm{OH}$ Scavenger on the Water Effect on Secondary Organic Aerosol Formation from Ozonolysis of Limonene, $\Delta^{3}$-Carene, and $\alpha$ Pinene, Environ. Sci. Technol., 42, 5938-5944, 2008.

Kang, E., Root, M. J., Toohey, D. W., and Brune, W. H.: Introducing the concept of Potential Aerosol Mass (PAM), Atmos. Chem. Phys., 7, 5727-5744, doi:10.5194/acp-7-5727-2007, 2007.

Kang, E., Toohey, D. W., and Brune, W. H.: Dependence of SOA oxidation on organic aerosol mass concentration and $\mathrm{OH}$ exposure: experimental PAM chamber studies, Atmos. Chem. Phys., 11, 1837-1852, doi:10.5194/acp-11-1837-2011, 2011.

Karjalainen, P., Timonen, H., Saukko, E., Kuuluvainen, H., Saarikoski, S., Aakko-Saksa, P., Murtonen, T., Bloss, M., Dal Maso, M., Simonen, P., Ahlberg, E., Svenningsson, B., Brune, W. H., Hillamo, R., Keskinen, J., and Rönkkö, T.: Time-resolved characterization of primary particle emissions and secondary particle formation from a modern gasoline passenger car, Atmos. 
Chem. Phys., 16, 8559-8570, doi:10.5194/acp-16-8559-2016, 2016.

Keller, A. and Burtscher, H.: A continuous photo-oxidation flow reactor for a defined measurement of the SOA formation potential of wood burning emissions, J. Aerosol Sci., 49, 9-20, 2012.

Khalizov, A. F., Earle, M. E., Johnson, W. J. W., Stubley, G. D., and Sloan, J. J.: Development and characterization of a laminar aerosol flow tube, Rev. Sci. Instrum., 77, 033102, doi:10.1063/1.2175958, 2006.

Kroll, J. H., Smith, J. D., Che, D. L., Kessler, S. H., Worsnop, D. R., and Wilson, K. R.: Measurement of fragmentation and functionalization pathways in the heterogeneous oxidation of oxidized organic aerosol, Phys. Chem. Chem. Phys., 11, 8005-8014, 2009.

Lambe, A. T., Ahern, A. T., Williams, L. R., Slowik, J. G., Wong, J. P. S., Abbatt, J. P. D., Brune, W. H., Ng, N. L., Wright, J. P., Croasdale, D. R., Worsnop, D. R., Davidovits, P., and Onasch, T. B.: Characterization of aerosol photooxidation flow reactors: heterogeneous oxidation, secondary organic aerosol formation and cloud condensation nuclei activity measurements, Atmos. Meas. Tech., 4, 445-461, doi:10.5194/amt-4-445-2011, $2011 \mathrm{a}$.

Lambe, A. T., Onasch, T. B., Massoli, P., Croasdale, D. R., Wright, J. P., Ahern, A. T., Williams, L. R., Worsnop, D. R., Brune, W. H., and Davidovits, P.: Laboratory studies of the chemical composition and cloud condensation nuclei $(\mathrm{CCN})$ activity of secondary organic aerosol (SOA) and oxidized primary organic aerosol (OPOA), Atmos. Chem. Phys., 11, 8913-8928, doi:10.5194/acp11-8913-2011, $2011 \mathrm{~b}$.

Lambe, A. T., Onasch, T. B., Croasdale, D. R., Wright, J. P., Martin, A. T., Franklin, J. P., Massoli, P., Kroll, J. H., Canagaratna, M. R., Brune, W. H., Worsnop, D. R., and Davidovits, P.: Transitions from functionalization to fragmentation reactions of laboratory secondary organic aerosol (SOA) generated from the $\mathrm{OH}$ oxidation of alkane precursors, Environ. Sci. Technol., 46, 5430-5437, 2012.

Lambe, A. T., Chhabra, P. S., Onasch, T. B., Brune, W. H., Hunter, J. F., Kroll, J. H., Cummings, M. J., Brogan, J. F., Parmar, Y., Worsnop, D. R., Kolb, C. E., and Davidovits, P.: Effect of oxidant concentration, exposure time, and seed particles on secondary organic aerosol chemical composition and yield, Atmos. Chem. Phys., 15, 3063-3075, doi:10.5194/acp-15-3063-2015, 2015.

Li, R., Palm, B. B., Ortega, A. M., Hlywiak, J., Hu, W., Peng, Z., Day, D. A., Knote, C., Brune, W. H., de Gouw, J. A., and Jimenez, J. L.: Modeling the radical chemistry in an oxidation flow reactor: Radical formation and recycling, sensitivities, and the $\mathrm{OH}$ exposure estimation equation, J. Phys. Chem. A, 119, 4418-4432, 2015.

Liu, B. Y. H. and Lee, K. W.: An aerosol generator of high stability, Am. Ind. Hyg. Assoc. J., 36, 861-865, 1975.

Loza, C. L., Coggon, M. M., Nguyen, T. B., Zuend, A., Flagan, R. C., and Seinfeld, J. H.: On the Mixing and Evaporation of Secondary Organic Aerosol Components, Environ. Sci. Technol., 47, 6173-6180, 2013.

Loza, C. L., Craven, J. S., Yee, L. D., Coggon, M. M., Schwantes, R. H., Shiraiwa, M., Zhang, X., Schilling, K. A., Ng, N. L., Canagaratna, M. R., Ziemann, P. J., Flagan, R. C., and Seinfeld, J. H.: Secondary organic aerosol yields of 12-carbon alkanes, Atmos. Chem. Phys., 14, 1423-1439, doi:10.5194/acp-14-14232014, 2014.
Matthews, P. S. J., Baeza-Romero, M. T., Whalley, L. K., and Heard, D. E.: Uptake of $\mathrm{HO}_{2}$ radicals onto Arizona test dust particles using an aerosol flow tube, Atmos. Chem. Phys., 14, 7397-7408, doi:10.5194/acp-14-7397-2014, 2014.

McDonald, A. T., Fox, R. W., and Van Dawoestine, R. V.: Effects of swirling inlet flow on pressure recovery in conical diffusers, AIAA J., 9, 2014-2018, 1971.

McVay, R. C., Cappa, C. D., and Seinfeld, J. H.: Vapor-Wall Deposition in Chambers: Theoretical Considerations, Environ. Sci. Technol., 48, 10251-10258, 2014.

McVay, R. C., Zhang, X., Aumont, B., Valorso, R., Camredon, M., La, Y. S., Wennberg, P. O., and Seinfeld, J. H.: SOA formation from the photooxidation of $\alpha$-pinene: systematic exploration of the simulation of chamber data, Atmos. Chem. Phys., 16, 27852802, doi:10.5194/acp-16-2785-2016, 2016.

Mehta, R. D. and Bradshaw, P.: Design rules for small low speed wind tunnels, Aeronaut. J., 83, 443-449, 1979.

Mikheev, V. B., Laulainen, N. S., Barlow, S. E., Knott, M., and Ford, I. J.: The laminar flow tube reactor as a quantitative tool for nucleation studies: Experimental results and theoretical analysis of homogeneous nucleation of dibutylphthalate, J. Chem. Phys., 113, 3704-3718, 2000.

Mori, Y. and Futagami, K.: Forced convective heat transfer in uniformly heated horizontal tubes (2nd report, theoretical study), Int. J. Heat Mass Tran., 10, 1801-1813, 1967.

Nah, T., McVay, R. C., Zhang, X., Boyd, C. M., Seinfeld, J. H., and $\mathrm{Ng}, \mathrm{N}$. L.: Influence of seed aerosol surface area and oxidation rate on vapor wall deposition and SOA mass yields: a case study with $\alpha$-pinene ozonolysis, Atmos. Chem. Phys., 16, 9361-9379, doi:10.5194/acp-16-9361-2016, 2016.

Nah, T., McVay, R. C., Pierce, J. R., Seinfeld, J. H., and Ng, N. L.: Constraining uncertainties in particle-wall deposition correction during SOA formation in chamber experiments, Atmos. Chem. Phys., 17, 2297-2310, doi:10.5194/acp-17-2297-2017, 2017.

Nguyen, T. B., Coggon, M. M., Bates, K. H., Zhang, X., Schwantes, R. H., Schilling, K. A., Loza, C. L., Flagan, R. C., Wennberg, P. O., and Seinfeld, J. H.: Organic aerosol formation from the reactive uptake of isoprene epoxydiols (IEPOX) onto nonacidified inorganic seeds, Atmos. Chem. Phys., 14, 3497-3510, doi:10.5194/acp-14-3497-2014, 2014.

Nguyen, T. B., Bates, K. H., Crounse, J. D., Schwantes, R. H., Zhang, X., Kjaergaard, H. G., Surratt, J. D., Lin, P., Laskin, A., Seinfeld, J. H., and Wennberg, P. O.: Mechanism of the hydroxyl radical oxidation of methacryloyl peroxynitrate (MPAN) and its pathway toward secondary organic aerosol formation in the atmosphere, Phys. Chem. Chem. Phys., 17, 17914-17926, 2015.

Ortega, A. M., Day, D. A., Cubison, M. J., Brune, W. H., Bon, D., de Gouw, J. A., and Jimenez, J. L.: Secondary organic aerosol formation and primary organic aerosol oxidation from biomass-burning smoke in a flow reactor during FLAME-3, Atmos. Chem. Phys., 13, 11551-11571, doi:10.5194/acp-1311551-2013, 2013.

Ortega, A. M., Hayes, P. L., Peng, Z., Palm, B. B., Hu, W., Day, D. A., Li, R., Cubison, M. J., Brune, W. H., Graus, M., Warneke, C., Gilman, J. B., Kuster, W. C., de Gouw, J., Gutiérrez-Montes, C., and Jimenez, J. L.: Real-time measurements of secondary organic aerosol formation and aging from ambient air in an oxidation flow reactor in the Los Angeles area, Atmos. Chem. Phys., 16, 7411-7433, doi:10.5194/acp-16-7411-2016, 2016. 
Palm, B. B., Campuzano-Jost, P., Ortega, A. M., Day, D. A., Kaser, L., Jud, W., Karl, T., Hansel, A., Hunter, J. F., Cross, E. S., Kroll, J. H., Peng, Z., Brune, W. H., and Jimenez, J. L.: In situ secondary organic aerosol formation from ambient pine forest air using an oxidation flow reactor, Atmos. Chem. Phys., 16, $2943-$ 2970, doi:10.5194/acp-16-2943-2016, 2016.

Peng, Z., Day, D. A., Stark, H., Li, R., Lee-Taylor, J., Palm, B. B., Brune, W. H., and Jimenez, J. L.: $\mathrm{HO}_{x}$ radical chemistry in oxidation flow reactors with low-pressure mercury lamps systematically examined by modeling, Atmos. Meas. Tech., 8, 4863-4890, doi:10.5194/amt-8-4863-2015, 2015.

Peng, Z., Day, D. A., Ortega, A. M., Palm, B. B., Hu, W., Stark, H., Li, R., Tsigaridis, K., Brune, W. H., and Jimenez, J. L.: Non-OH chemistry in oxidation flow reactors for the study of atmospheric chemistry systematically examined by modeling, Atmos. Chem. Phys., 16, 4283-4305, doi:10.5194/acp-16-4283-2016, 2016.

Prakash, R., Christopher, D., and Kumarrathinam, K.: CFD analysis of flow through a conical exhaust diffuser, Int. J. Res. Eng. Technol., 3, 239-248, 2014.

Schilling, F.-K. A., Yee, L. D., Loza, C. L., Coggon, M. M., Schwantes, R., Zhang, X., Dalleska, N. F., and Seinfeld, J. H.: Secondary Organic Aerosol Composition from C-12 Alkanes, J. Phys. Chem. A, 119, 4281-4297, 2015.

Schwantes, R. H., Teng, A. P., Nguyen, T. B., Coggon, M. M., Crounse, J. D., St Clair, J. M., Zhang, X., Schilling, K. A., Seinfeld, J. H., and Wennberg, P. O.: Isoprene $\mathrm{NO}_{3}$ Oxidation Products from the $\mathrm{RO}_{2}+\mathrm{HO}_{2}$ Pathway, J. Phys. Chem. A, 119, 10158-10171, 2015.

Seinfeld, J. H. and Pandis, S. N.: Atmospheric Chemistry and Physics: From Air Pollution to Climate Change, 3 edn., Wiley Sons, Hoboken, New Jersey, USA, 2016.

Sellier, M., Grayson, J. W., Renbaum-Wolff, L., Song, M., and Bertram, A. K.: Estimating the viscosity of a highly viscous liquid droplet through the relaxation time of a dry spot, J. Rheol., 59, 733-750, 2015.

Seltsam, M. M.: Experimental and theoretical study of wide-angle diffuser flow with screens, AIAA J., 33, 2092-2100, 1995.

Siegwarth, D. P., Mikesell, R. D., Readal, T. C., and Hanratty, T. J.: Effect of secondary flow on the temperature field and primary flow in a heated horizontal tube, Int. J. Heat Mass Tran., 12, 1535-1552, 1969.

Simonen, P., Saukko, E., Karjalainen, P., Timonen, H., Bloss, M., Aakko-Saksa, P., Rönkkö, T., Keskinen, J., and Dal Maso, M.: A New Oxidation Flow Reactor for Measuring Secondary Aerosol Formation of Rapidly Changing Emission Sources, Atmos. Meas. Tech. Discuss., doi:10.5194/amt-2016-300, in review, 2016.

Slowik, J. G., Wong, J. P. S., and Abbatt, J. P. D.: Real-time, controlled $\mathrm{OH}$-initiated oxidation of biogenic secondary organic aerosol, Atmos. Chem. Phys., 12, 9775-9790, doi:10.5194/acp12-9775-2012, 2012.
Smith, J. D., Kroll, J. H., Cappa, C. D., Che, D. L., Liu, C. L., Ahmed, M., Leone, S. R., Worsnop, D. R., and Wilson, K. R.: The heterogeneous reaction of hydroxyl radicals with submicron squalane particles: a model system for understanding the oxidative aging of ambient aerosols, Atmos. Chem. Phys., 9, 3209-3222, doi:10.5194/acp-9-3209-2009, 2009.

Sparrow, E. M., Abraham, J. P., and Minkowycz, W. J.: Flow Separation in a diverging conical duct: Effect of Reynolds number and divergence angle, Int. J. Heat Mass Tran., 52, 3079-3083, 2009.

St. Clair, J. M., McCabe, D. C., Crounse, J. D., Steiner, U., and Wennberg, P. O.: Chemical ionization tandem mass spectrometer for the in situ measurement of methyl hydrogen peroxide, Rev. Sci. Instrum., 81, 094102, doi:10.1063/1.3480552, 2010.

Tavoularis, S.: Measurement in Fluid Mechanics, Cambridge University Press, New York, USA, 2005.

Taylor, G.: Dispersion of soluble matter in solvent flowing slowly through a tube, P. Roy. Soc. Lond. A Mat., 219, 186-203, 1953.

Thornton, J. and Abbatt, J. P. D.: Measurements of $\mathrm{HO}_{2}$ uptake to aqueous aerosol: Mass accommodation coefficients and net reactive loss, J. Geophys. Res.-Atmos., 110, D08309, doi:10.1029/2004JD005402, 2005.

Tkacik, D. S., Lambe, A. T., Jathar, S., Li, X., Presto, A. A., Zhao, Y., Blake, D., Meinardi, S., Jayne, J. T., Croteau, P. L., and Robinson, A. L.: Secondary Organic Aerosol Formation from inUse Motor Vehicle Emissions Using a Potential Aerosol Mass Reactor, Environ. Sci. Technol., 48, 11235-11242, 2014.

White, F. M.: Fluid Mechanics, McGraw-Hill, New York, USA, 2008.

Yee, L. D., Craven, J. S., Loza, C. L., Schilling, K. A., Ng, N. L., Canagaratna, M. R., Ziemann, P. J., Flagan, R. C., and Seinfeld, J. H.: Effect of chemical structure on secondary organic aerosol formation from $\mathrm{C}_{12}$ alkanes, Atmos. Chem. Phys., 13, 1112111140, doi:10.5194/acp-13-11121-2013, 2013.

Zhang, X., Cappa, C. D., Jathar, S. H., McVay, R. C., Ensberg, J. J., Kleeman, M. J., and Seinfeld, J. H.: Influence of vapor wall loss in laboratory chambers on yields of secondary organic aerosol, $\mathrm{P}$. Natl. Acad. Sci. USA, 111, 5802-5807, 2014.

Zhang, X., McVay, R. C., Huang, D. D., Dalleska, N. F., Aumont, B., Flagan, R. C., and Seinfeld, J. H.: Formation and evolution of molecular products in alpha-pinene secondary organic aerosol, $\mathrm{P}$. Natl. Acad. Sci. USA, 112, 14168-14173, 2015.

Zhang, Y., Sanchez, M. S., Douet, C., Wang, Y., Bateman, A. P., Gong, Z., Kuwata, M., Renbaum-Wolff, L., Sato, B. B., Liu, P. F., Bertram, A. K., Geiger, F. M., and Martin, S. T.: Changing shapes and implied viscosities of suspended submicron particles, Atmos. Chem. Phys., 15, 7819-7829, doi:10.5194/acp-15-78192015, 2015. 